This is an electronic reprint of the original article. This reprint may differ from the original in pagination and typographic detail.

Author(s): Tuononen, Heikki; Armstrong, Andrea

Title: $\quad$ Theoretical investigation of paramagnetic group 13 diazabutadiene radicals: insights into the prediction and interpretation of EPR spectroscopy parameters

Year: $\quad 2006$

Version:

Please cite the original version:

Tuononen, H., \& Armstrong, A. (2006). Theoretical investigation of paramagnetic group 13 diazabutadiene radicals: insights into the prediction and interpretation of EPR spectroscopy parameters. Dalton Transactions, (15), 1885-1894.

https://doi.org/10.1039/B514104D

All material supplied via JYX is protected by copyright and other intellectual property rights, and duplication or sale of all or part of any of the repository collections is not permitted, except that material may be duplicated by you for your research use or educational purposes in electronic or print form. You must obtain permission for any other use. Electronic or print copies may not be offered, whether for sale or otherwise to anyone who is not an authorised user. 


\title{
Theoretical investigation of paramagnetic group 13 diazabutadiene radicals: Insights into the prediction and interpretation of EPR spectroscopy parameters $\dagger$
}

\author{
Heikki M. Tuononen $* a$ and Andrea F. Armstrong ${ }^{b}$ \\ a Department of Chemistry, University of Jyväskylä, P.O. Box 35, FI-40014 Jyväskylä, \\ Finland. E-mail: hetuonon@cc.jyu.fi; Tel: +358-14-260-2618; Fax: +358-14-260- \\ 2501 \\ ${ }^{b}$ Department of Chemistry, McMaster University, 1280 Main St. W., Hamilton, Ontario,
} Canada L8S 4MI

$\dagger$ Electronic supplementary information (ESI) available: tables of calculated hyperfine coupling constants for compounds $\mathbf{6}-\mathbf{M}^{\mathbf{R}} \mathbf{X}$ and $\mathbf{7 -}-\mathbf{M}^{\mathbf{R}} \mathbf{X}$.

The electronic structures and the spin density distributions of the group 13 1,4diaza $(1,3)$ butadiene $(\mathrm{DAB})$ radicals $\left[(\mathrm{R}-\mathrm{DAB})_{2} \mathrm{M}\right]^{\circ}, \quad\left[(\mathrm{R}-\mathrm{DAB}) \mathrm{MX}_{2}\right]^{\circ}$, and $\{[(\mathrm{R}-$ $\left.-\mathrm{DAB}) \mathrm{MX}_{2}\right\}^{\bullet \bullet}\left(\mathrm{M}=\mathrm{Al}, \mathrm{Ga}, \mathrm{In} ; \mathrm{X}=\mathrm{F}, \mathrm{Cl}, \mathrm{Br}, \mathrm{I} ; \mathrm{R}=\mathrm{H}, \mathrm{Me},{ }^{\mathrm{t}} \mathrm{Bu}, \mathrm{Ph}\right)$ are studied using density functional theory at both non-relativistic and relativistic levels of theory. The calculations demonstrate that all systems share a qualitatively similar electronic structure and are primarily ligand centred $\pi$-radicals. The calculated metal, nitrogen, and hydrogen hyperfine couplings are found to be independent of the identity of the R-group and the halogen atom. They are, however, dependent on the geometry and oxidation state of the metal centre. Both observed trends contrast what has previously been deduced from the interpretation of experimental EPR and ENDOR spectra. Good agreement between the calculated and experimentally determined hyperfine coupling constants is found only for 
some of the studied systems. Instances where significant discrepancies between the calculated and experimental values exist can be attributed to the tendency of these systems toward complex solution behaviour, which results in differences between the solid state and solution structures of certain complexes. A careful re-evaluation of the experimental data as well as calculated reaction energies lends strong support to this hypothesis. However, further studies are needed before the identity of some of the studied radical species in solution can be unambiguously determined.

\section{Introduction}

During the past quarter of a century, 1,4-diaza-1,3-butadiene (DAB) ligands (1) have attracted considerable attention as useful reagents in organometallic chemistry due to their coordination and redox properties. The lone pairs of the nitrogen atoms and the $\pi$ electrons of the $\mathrm{C}=\mathrm{N}$ bonds allow these molecules to act both as $n$ - and $\pi$-electron donors, which allows coordination to metals using $2,4,6$, or 8 electrons. In addition, the identities of the four substituents on the $\mathrm{N}=\mathrm{C}-\mathrm{C}=\mathrm{N}$ backbone can be easily varied, allowing for the steric and electronic properties of the ligand to be fine-tuned; the ligand substituted at the nitrogen atoms with the bulky ${ }^{\mathrm{t}} \mathrm{Bu}$ group has been widely employed in research.

At present, DAB ligands have been coordinated to nearly all the transition metal elements, ${ }^{1}$ to lanthanoids such as europium and gadolinium ${ }^{2}$, as well as to a range of main group elements including silicon ${ }^{3}$ and germanium. ${ }^{4}$ A number of the synthesized metal complexes are catalytically active and can effect a broad spectrum of chemical reactions. ${ }^{5}$ In recent years, a growing interest in complexes of the DAB ligand which contain group 
13 elements has emerged and many novel systems have arisen from this work. ${ }^{6}$ Of especial importance have been the anionic species $[(\mathrm{DAB}) \mathrm{M}:]^{-}(\mathrm{M}=\mathrm{Al}, \mathrm{Ga})^{6 \mathrm{~d}, \mathrm{e}}$ which are isoelectronic with the stable $N$-heterocyclic Arduengo-type carbenes [(DAB)C:]. ${ }^{7}$

More closely aligned with our research interests are the vast number of metal complexes which formally contain the DAB ligand as a monoanion radical (2), formed from the one-electron reduction of the parent species 1. Paramagnetic DAB complexes of alkaline earth metals, ${ }^{8,9}$ lithium, ${ }^{9}$ and zinc ${ }^{8 b, 9,10}$ have been known for a number of years, while more recent work in this area has resulted in the isolation of variety of group 13 complexes containing the DAB anion radical. ${ }^{6 f, 11}$ Very recently the first complexes of group 13 elements with two paramagnetic DAB ligands were reported. ${ }^{11 e-h}$ All these species have been characterized primarily by EPR spectroscopy and X-ray crystallography, though other experimental techniques including cyclic voltammetry and photoelectron spectroscopy have also been employed.
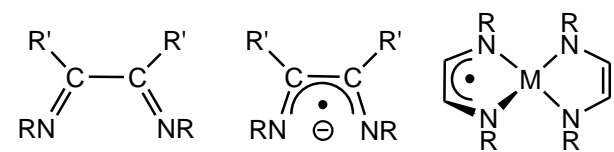

1

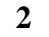

3
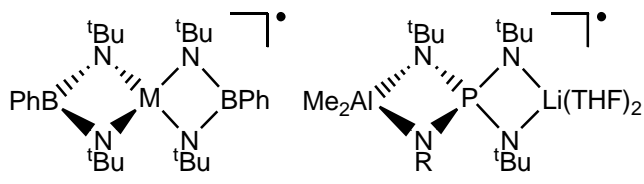

4

5

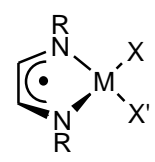

6

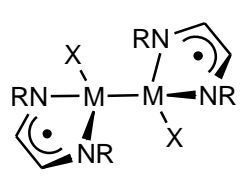

7

Despite the wealth of experimental data available for these systems, significantly less is known regarding their electronic structure and, especially, their spin density distributions. Although EPR spectroscopy offers a unique experimental means of 
acquiring much of this information, the majority of the spectra obtained for the paramagnetic group $13 \mathrm{DAB}$ complexes are poorly resolved due to hyperfine couplings to a number of spin-active nuclei. In consequence, it is difficult to extract accurate values of the hyperfine coupling constants (HFCCs) and, thus, the spin densities, from these spectra. In many cases, this has led to spectral assignments that are tentative at best. ${ }^{11}$ The spirocyclic systems $\left[\left({ }^{\mathrm{t}} \mathrm{Bu}-\mathrm{DAB}\right)_{2} \mathrm{M}\right]^{\bullet}\left(\mathbf{3}-\mathbf{M}^{\mathrm{tBu}}, \mathrm{M}=\mathrm{Al}, \mathrm{Ga}\right)$ offer an extreme example of the controversies reported for these systems, ${ }^{11 \mathrm{a}, \mathrm{b}}$ inadequate spectral analysis initially lead to an incorrect assignment of different oxidation states for the group 13 elements in 3$\mathbf{A l}^{\mathrm{tBu}}\left(\mathrm{M}^{\mathrm{III}}\right)$ and $\mathbf{3 - G a} \mathbf{t}^{\mathrm{tBu}}\left(\mathrm{M}^{\mathrm{II}}\right)$ whereas more detailed spectral ${ }^{12}$ and theoretical ${ }^{12 b, 13}$ analyses have demonstrated that both systems contain a group 13 atom in the $\mathrm{M}^{\mathrm{III}}$ oxidation state.

While information regarding the electronic structures and spin densities of radical systems can also be obtained through high-level theoretical calculations, only two computational studies of the DAB complexes of p-block elements have been reported to date. ${ }^{13}$ Both studies have been confined to the investigation of spirocyclic complexes of the type $\mathbf{3}-\mathbf{M}^{\mathbf{R}}$, and only one reports the calculated spin densities for the group 13 metal derivatives. ${ }^{13 \mathrm{~b}}$ This is somewhat surprising considering the vast number of paramagnetic group $13 \mathrm{DAB}$ complexes reported recently and the unexpected, and at times conflicting, spectroscopic data that they have yielded. ${ }^{11 \mathrm{c}-\mathrm{h}}$ A high-level theoretical study of these systems is expected to give valuable information about their spin densities which would facilitate a re-interpretation of the experimental data and perhaps clarify some of the controversy which surrounds these radicals. 
We have recently shown that near-quantitative spin densities and HFCCs can be obtained for the spirocyclic group 13 boraamidinate $\left\{\left[\mathrm{PhB}\left(\mu-\mathrm{N}^{\mathrm{t} B u}\right)_{2}\right]_{2} \mathrm{M}\right\}^{\bullet}(4, \mathrm{M}=\mathrm{B}, \mathrm{Al}$, $\mathrm{Ga}, \mathrm{In})^{14}$ and tetraimidophosphate $\left\{\mathrm{Me}_{2} \mathrm{Al}\left[(\mu-\mathrm{NR})\left(\mu-\mathrm{N}^{\mathrm{t}} \mathrm{Bu}\right) \mathrm{P}\left(\mu-\mathrm{N}^{\mathrm{t}} \mathrm{Bu}\right)_{2}\right] \mathrm{Li}(\mathrm{THF})_{2}\right\}^{\bullet}(\mathbf{5}, \mathrm{R}$ $\left.={ }^{\mathrm{t}} \mathrm{Bu}, \mathrm{SiMe}_{3}\right)^{15}$ radicals using methods based on density functional theory. Our success, especially with the boraamidinate systems $\mathbf{4}$, strongly suggests that similar calculations will also yield accurate results for the structurally related group 13 DAB complexes. Herein we report DFT calculations on the electronic and molecular structures of group 13 DAB systems $\mathbf{3}-\mathbf{M}^{\mathbf{R}}$, the related monocyclic radicals $\left[(\mathrm{R}-\mathrm{DAB}) \mathrm{MX}_{2}\right]^{\bullet}\left(\mathbf{6}-\mathbf{M}^{\mathbf{R}} \mathbf{x}, \mathbf{M}=\mathrm{Al}\right.$,

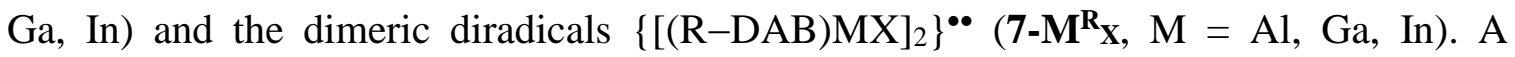
thorough study using a variety of substituent groups $\mathrm{H}, \mathrm{Me},{ }^{\mathrm{t}} \mathrm{Bu}$, and $\mathrm{Ph}$ (superscript $\mathrm{R}$ in compound number) and different halogen atoms $\mathrm{F}, \mathrm{Cl}, \mathrm{Br}$, and $\mathrm{I}$ (subscript $\mathrm{X}$ in compound number) has been carried out. From this, a detailed picture of the extent of spin delocalization in these systems and how it is influenced by different substituents has emerged. These results will be used to aid in the interpretation of experimental EPR and ENDOR data.

\section{Results and discussion}

\section{Spirocyclic group 13 diazabutadiene monoradicals}

The first paramagnetic spirocyclic diazabutadiene complexes of aluminium $\left[\left({ }^{\mathrm{t}} \mathrm{Bu}-\mathrm{DAB}\right)_{2} \mathrm{Al}\right]^{\bullet}\left(\mathbf{3}-\mathbf{A l}^{\mathrm{tBu}}\right)^{11 \mathrm{a}}$ and gallium $\left.\left[\left({ }^{\mathrm{t}} \mathrm{Bu}-\mathrm{DAB}\right)\right]_{2} \mathrm{Ga}\right]^{\bullet}\left(\mathbf{3}-\mathbf{G a}^{\mathrm{tBu}}\right)^{11 \mathrm{~b}}$ were reported a number of years ago. These compounds were characterized both in solution by EPR spectroscopy, and in the solid state by X-ray crystallography and photoelectron

spectroscopy. The structural analyses of $\mathbf{3}-\mathbf{A l}^{\mathbf{t B u}}$ and $\mathbf{3 - G \mathbf { G } ^ { \mathbf { t B u } }}$ revealed the presence of two 
inequivalent DAB ligands in each molecule, with distinctly different metrical parameters observed throughout the two DAB moieties. Interpretation of the solution EPR spectra of these species led to the rather curious assignment of oxidation states +3 and +2 for the

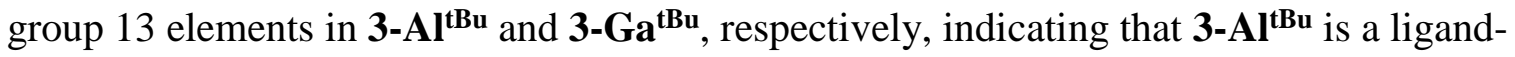
centred radical with one singly and one doubly reduced ligand, while $\mathbf{3 - G a} \mathbf{G}^{\mathbf{t B u}}$ would be a gallium-centred radical. This controversial claim was later refuted by a re-interpretation

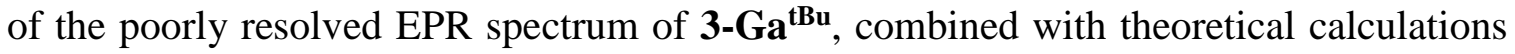
which suggested that $\mathbf{3 - G} \mathbf{G}^{\mathbf{t B u}}$ is a ligand-centred radical like $\mathbf{3}-\mathbf{A l}^{\mathbf{t B u}} \cdot{ }^{12 \mathrm{~b}, 13}$ Recently, the first derivatives of $\mathbf{3 - G \mathbf { G } ^ { \mathbf { R } }}$ which contain aromatic substituents on the DAB nitrogen atoms have been isolated and both structurally and spectroscopically characterized. ${ }^{11 \mathrm{~d}, \mathrm{~h}}$ The EPR spectrum the complex $\left[(\mathrm{Dipp}-\mathrm{DAB})_{2} \mathrm{Ga}\right]^{\bullet}\left(\mathbf{3 - G a}^{\mathrm{Dipp}}\right.$, Dipp $=$ 2,6-diiso-

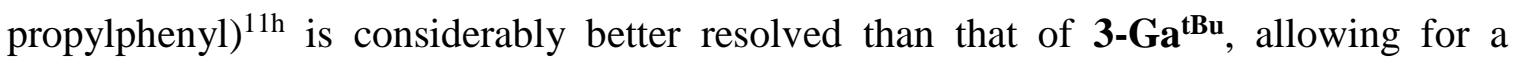
definitive interpretation of the observed hyperfine couplings and confirming that the unpaired electron is ligand-centred and interacts primarily with only one of the DAB units. Because systems of type $\mathbf{3}$ have been well-characterized in the past, they will provide a useful benchmark in determining the accuracy of our calculated metrical parameters and hyperfine coupling constants (HFCCs).

Calculations were carried out on a series of compounds of types $\mathbf{3}-\mathbf{M}^{\mathbf{R}}$, varying the identities of the substituents on the DAB nitrogen atoms. Calculated metrical parameters for selected compounds are compiled in Table 1 along with experimental data; calculated hyperfine coupling constants for all relevant spin-active nuclei are listed in Table 2. As a whole, the calculated bond lengths and bond angles accurately reproduce those obtained from X-ray structural analyses, ${ }^{11 \mathrm{a}, \mathrm{b}, \mathrm{d}, \mathrm{h}}$ indicating that the chosen level of 
theory is sufficient for these systems. In complexes of types $\mathbf{3 - A l} \mathbf{A}^{\mathbf{R}}$ and $\mathbf{3 - G} \mathbf{a}^{\mathbf{R}}$, the central group 13 element has a tetrahedral coordination environment and the molecules display $C_{2 \mathrm{v}}$ symmetry, with the exception of $\mathbf{3}-\mathbf{A l}^{\mathbf{P h}}$ and $\mathbf{3 - G a} \mathbf{G}^{\mathbf{P h}}$, which are $C_{2}$ symmetric due to the orientation of the phenyl groups. Previous theoretical work ${ }^{13 b}$ has shown that the global energy minimum for the indium analogues $\mathbf{3}-\mathbf{I n}^{\mathbf{R}}$ has $C_{2}$ symmetry, where the indium atom is slightly pyramidalized: however, for ease of comparison with $\mathbf{3}-\mathbf{A l}^{\mathbf{R}}$ and 3-Ga ${ }^{\mathbf{R}}$, the geometries of the calculated species $\mathbf{3}-\mathbf{I n}^{\mathbf{R}}$ have been constrained such that the coordination sphere of the indium atom is tetrahedral.

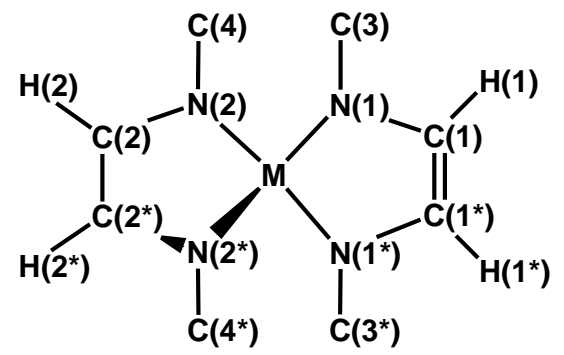

The singly occupied molecular orbital (SOMO) of $\mathbf{3 - A \mathbf { A } ^ { \mathbf { t B u } }}$ is depicted in Figure 1, and is bonding along the $\mathrm{C}-\mathrm{C}$ bond and anti-bonding between the carbon and nitrogen atoms. Varying the substituents on the DAB nitrogen atoms does not result in significant changes to the SOMO; similarly, changing the identity of the central group 13 element from aluminium to gallium to indium does not affect its general features. Composed primarily of carbon and nitrogen $p$-orbitals of one DAB ligand, the SOMO has no $s$ contribution from the central metal and only minute contributions from the second DAB moiety. In consequence, relatively small hyperfine couplings to the group 13 atom and the nitrogen atoms of one DAB ligand are expected. The SOMO also has no contribution from the DAB hydrogen atoms which suggests that any observed ${ }^{1} \mathrm{H}$ coupling is entirely due to spin polarization effects. 
Mulliken population analysis indicated that the spin densities in $\mathbf{3}-\mathbf{M}^{\mathbf{R}}$ are nearly equally distributed throughout the carbon and nitrogen atoms of one DAB unit. The lack of variation in the calculated HFCCs (Table 2) for a particular atom regardless of the identity of the DAB nitrogen substituents is consistent with the aforementioned constancy

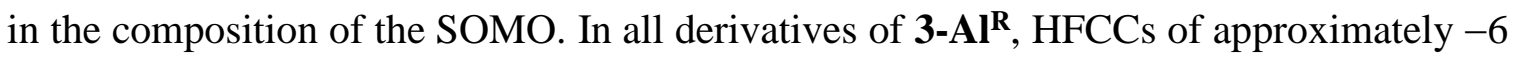
$\mathrm{G}$ are predicted to the aluminium atom and to the ${ }^{1} \mathrm{H}$ atoms of the backbone of one DAB ligand. Slightly greater variation in the magnitude of the ${ }^{14} \mathrm{~N}$ HFCC is observed, with values ranging between $2.7 \mathrm{G}$ and $3.6 \mathrm{G}$ : the $\mathrm{HFCC}$ was found to increase from $\mathbf{3 - A \mathbf { l } ^ { \mathrm { H } }}$ to 3-Al ${ }^{\mathrm{Me}}$ to 3-Al ${ }^{\mathrm{Bu}}$ i.e. with the steric bulk of the R-group bonded to the nitrogen atom. The lone aromatic derivative $\mathbf{3}-\mathbf{A l}^{\mathbf{P h}}$ is predicted to have a ${ }^{14} \mathrm{~N}$ HFCC of intermediate size (3.1 G) presumably due to the inductive effect of the phenyl group. Small hyperfine couplings to the hydrogen and nitrogen atoms of the second DAB ligand are also anticipated, with a ${ }^{14} \mathrm{~N}$ HFCC of approximately $1 \mathrm{G}$ and hydrogen couplings of $c a .0 .5 \mathrm{G}$ for all 3-Al ${ }^{\mathbf{H}}, \mathbf{3}-\mathbf{A l}{ }^{\mathrm{Me}}$, and $\mathbf{3}-\mathbf{A l}{ }^{\mathrm{tBu}}$; a significant decrease in the ${ }^{1} \mathrm{H}$ HFCC was calculated

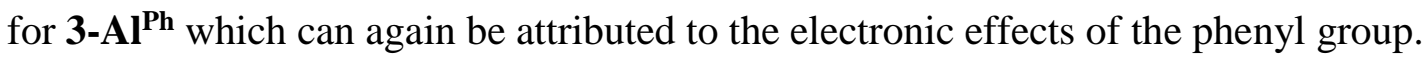

These same trends in ${ }^{14} \mathrm{~N}$ and ${ }^{1} \mathrm{H}$ hyperfine coupling constants are observed for the gallium and indium systems $\mathbf{3}-\mathbf{G a}^{\mathbf{R}}$ and $\mathbf{3}-\mathbf{I} \mathbf{n}^{\mathbf{R}}$, and no significant variation in their magnitudes over those in the aluminium congeners is predicted. The close agreement between the ${ }^{1} \mathrm{H}$ and ${ }^{14} \mathrm{~N}$ HFCCs of $\mathbf{3}-\mathbf{A l}{ }^{\mathbf{R}}, \mathbf{3}-\mathbf{G a}^{\mathbf{R}}$, and $\mathbf{3}-\mathbf{I n}^{\mathbf{R}}$ is not unexpected based on the strong similarities between the SOMOs of these three radical systems. As was seen for the aluminium nucleus of $\mathbf{3}-\mathbf{A l} \mathbf{I}^{\mathbf{R}}$, the ${ }^{69} \mathrm{Ga}$ and ${ }^{115}$ In HFCCs are essentially static at $-22 \mathrm{G}$ and $-33 \mathrm{G}$, respectively, regardless of the substituents on the DAB ligands. The ratios of the calculated ${ }^{27} \mathrm{Al}:{ }^{69} \mathrm{Ga}$ and ${ }^{27} \mathrm{Al}:{ }^{115}$ In HFCCs are consistent with the relative 
values of the isotropic hyperfine constants of the free nuclei demonstrating again the similarity between the electronic structures of $\mathbf{3 - M ^ { \mathbf { R } }}{ }^{16}$ The EPR spectra of the hitherto uncharacterized spirocyclic systems $\mathbf{3}-\mathbf{I n}^{\mathbf{R}}$ are predicted to have a width of around $350 \mathrm{G}$, with a $-30 \mathrm{G}$ hyperfine coupling to indium resulting in a dectet signal which will be further split into overlapping heptets due to coupling of the unpaired electron to two magnetically equivalent ${ }^{14} \mathrm{~N}$ and two equivalent ${ }^{1} \mathrm{H}$ atoms.

The calculated HFCCs compare favourably with the experimental values that have been determined for $\mathbf{3}-\mathbf{A l}^{\mathrm{tBu}},{ }^{12 \mathrm{a}} \mathbf{3}-\mathbf{G a}^{\mathrm{tBu}},{ }^{12 \mathrm{a}}$ and $\mathbf{3}-\mathbf{G a}^{\text {Dipp }}{ }^{11 \mathrm{~h}}$ It should be noted that the experimental EPR spectra of both $\mathbf{3}-\mathbf{A l}^{\mathbf{t B u}}$ and $\mathbf{3}-\mathbf{G a}^{\mathbf{t B u}}$ are very poorly resolved, and that the HFCCs for these species have only been estimated; a reasonable simulation of the experimental spectrum of $\mathbf{3}-\mathbf{A l}^{\mathbf{t B u}}$ has been reported by assuming identical HFCCs of $5 \mathrm{G}$ to the five spin-active nuclei $\left(1 \times{ }^{1} \mathrm{H}, 2 \times{ }^{14} \mathrm{~N}, 1 \times{ }^{27} \mathrm{Al}\right) .{ }^{12 \mathrm{a}} \mathrm{EPR}$ spectra of both $\mathbf{3}-\mathbf{G a}^{\mathrm{t}} \mathrm{Bu}$ $11 \mathrm{~b}$ and 3-Ga $\mathbf{a}^{\text {Dipp } 11 \mathrm{~h}}$ have been reported in the literature; however, the extreme linebroadening observed for 3-Ga $\mathbf{a}^{\mathbf{t B u}}$ has prevented the determination of accurate HFCCs for this radical and only the magnitudes of the ${ }^{69,71} \mathrm{Ga}$ HFCCs have been determined. ${ }^{12 \mathrm{a}}$ In contrast, a good simulation of the experimental EPR spectrum of 3-Ga ${ }^{\text {Dipp }}$ has been obtained using HFCCs to ${ }^{69,71} \mathrm{Ga}(17.0 \mathrm{G}, 20.5 \mathrm{G})$, two equivalent ${ }^{14} \mathrm{~N}$ atoms $(6.00 \mathrm{G})$, and two equivalent ${ }^{1} \mathrm{H}$ nuclei $(5.80 \mathrm{G}) .{ }^{11 \mathrm{~h}}$ These values are in good agreement with the calculated values for the closely related species $\mathbf{3 - G a}{ }^{\mathbf{P h}}$ (Table 2). The most notable discrepancies between the experimental and calculated values are the underestimation of the ${ }^{14} \mathrm{~N}$ HFCCs, which was also observed in our previous investigation of the related boraamidinate ${ }^{14}$ complexes $\mathbf{4}$, and the slight overestimation of the ${ }^{1} \mathrm{H}$ HFCCs. As the hyperfine couplings to the hydrogen atoms of the DAB backbone arise due to spin- 
polarization, this behaviour is to be expected since unrestricted calculations are known to overestimate the amount of the effect. ${ }^{17}$

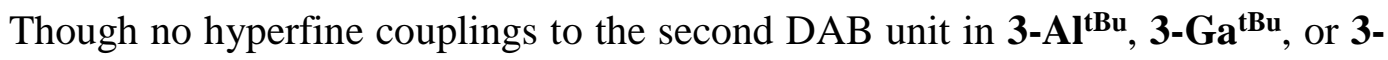
Ga $^{\text {Dipp }}$ have been detected experimentally, the experimental spectra all have relatively broad line shapes and display an S-curve, indicative of the presence of small unresolved HFCCs. ${ }^{11 b, h ; 12 a}$ ENDOR analysis of 3-Ga ${ }^{\text {Dipp }}$ has confirmed the presence of small (ca. 1 G) ${ }^{1} \mathrm{H}$ couplings which the authors assigned to the hydrogen atoms of the isopropylmethyl groups. ${ }^{11 \mathrm{~h}}$ However, the computational results suggest an alternative assignment of these HFCCs, as ${ }^{1} \mathrm{H}$ hyperfine couplings of this magnitude are predicted to the two $\mathrm{C}-\mathrm{H}$ hydrogen atoms of the second DAB unit of $\mathbf{3 - G a} \mathbf{G h}^{\mathbf{P h}}$.

The good correlation between the experimental and calculated HFCCs for systems 3-Al ${ }^{\mathbf{R}}$ and $\mathbf{3 - G a} \mathbf{G}^{\mathbf{R}}$ indicates that calculations at this level are appropriate for both of these systems and thus should provide useful insights and semi-quantitative results regarding the spin density distributions of the related radicals $\mathbf{6}-\mathbf{M}^{\mathbf{R}} \mathbf{x}$ and $\mathbf{7 -} \mathbf{M}^{\mathbf{R}} \mathbf{x}$.

\section{Monocyclic group 13 diazabutadiene monoradicals}

The paramagnetic gallium diazabutadiene complexes $\left[(\mathrm{R}-\mathrm{DAB}) \mathrm{GaI}_{2}\right]^{\bullet}(\mathrm{R}=\mathrm{Dipp}, \mathbf{6}-$ $\mathbf{G a}^{\text {Dipp }} \mathbf{I} ; \mathrm{R}=$ Mes, 6-Ga ${ }^{\text {Mes }} \mathbf{I}$ R = Xyl, 6-Ga ${ }^{\mathbf{X y l}} \mathbf{I}$ ) have been synthesized by the reduction of the corresponding neutral R-DAB ligands with Green's "GaI"; 1 d,e,h the alkyl derivative $\left[\left({ }^{\mathrm{t}} \mathrm{Bu}-\mathrm{DAB}\right) \mathrm{GaI}_{2}\right]^{\bullet} \quad\left(\mathbf{6}-\mathbf{G a}^{\mathrm{tBu}} \mathrm{I}\right)$ has also been reported as the minor product from the analogous reaction involving the ${ }^{\mathrm{t}} \mathrm{Bu}-\mathrm{DAB}$ ligand. ${ }^{11 \mathrm{e}}$ All four of these compounds have been characterized in the solid state, but EPR spectra have only been reported for 6$\mathbf{G a}^{\mathrm{tBu}_{\mathrm{I}} \text { and 6-Gapp }} \mathbf{\text { I. }}$ 
The experimental EPR spectrum of $\mathbf{6}-\mathbf{G a}^{\text {Dipp }_{\mathbf{I}}}$ is very poorly resolved, and the number and magnitude of the HFCCs present could only be estimated. ${ }^{11 \mathrm{~d}, \mathrm{~h}}$ The initial

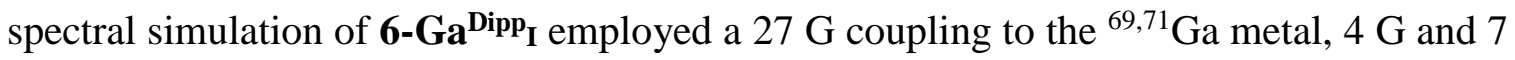
$\mathrm{G}$ couplings to the imine hydrogen and nitrogen atoms, respectively, and a $8 \mathrm{G}$ coupling to each of the two ${ }^{127}$ I nuclei. ${ }^{11 \mathrm{~d}}$ A new spectral interpretation which employs a drastically different iodine HFCCs $(<1.5 \mathrm{G})$ was recently published. ${ }^{11 \mathrm{~h}}$ The authors rationalized the occurrence of only relatively small couplings to the ${ }^{127} \mathrm{I}$ nuclei in $\mathbf{6}-\mathbf{G a}^{\text {Dipp }} \mathbf{I}$ with experimental data available for other known systems of the type $\mathbf{6}-\mathbf{M}^{\mathbf{R}} \mathbf{I}$ (vide infra) and for the structurally related radicals $\left\{\left({ }^{\mathrm{t}} \mathrm{Bu}-\mathrm{DAB}\right) \mathrm{Ga}\left[\mathrm{Pn}\left(\mathrm{SiMe}_{3}\right)_{2}\right]_{2}\right\}^{\bullet}$ and $\left\{\left({ }^{\mathrm{t}} \mathrm{Bu}-\mathrm{DAB}\right) \mathrm{Ga}\left[\mathrm{Pn}\left(\mathrm{SiMe}_{3}\right)_{2}\right][\mathrm{I}]\right\}^{\bullet}(\mathrm{Pn}=\mathrm{N}, \mathrm{P}, \mathrm{As})$ which all display negligible couplings to the remote group 15 and 17 nuclei. However, no attempt was made to confirm either of these sets of HFCCs by theoretical means.

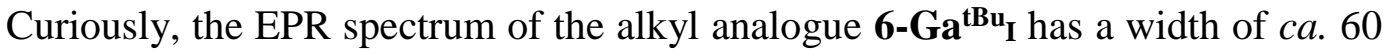
$\mathrm{G},{ }^{11 \mathrm{e}}$ while the EPR spectrum of $\mathbf{6 - G a} \mathbf{G}^{\text {Dipp }_{\mathbf{I}}}$ is nearly $200 \mathrm{G}$ in width, ${ }^{11 \mathrm{~d}, \mathrm{~h}}$ indicating that significantly smaller hyperfine couplings are present in $\mathbf{6}-\mathbf{G a}^{\mathbf{t B u}} \mathbf{I}$. A satisfactory simulation of the experimental spectrum of $\mathbf{6}-\mathbf{G a}^{\mathbf{t B u}} \mathbf{I}$ has been obtained by including HFCCs to two ${ }^{1} \mathrm{H}$ atoms $(1.4 \mathrm{G})$, two ${ }^{14} \mathrm{~N}$ nuclei $(8.62 \mathrm{G})$, two ${ }^{127} \mathrm{I}$ centres $(1.3 \mathrm{G})$, and an appropriate combination of ${ }^{69} \mathrm{Ga}(1.3 \mathrm{G})$ and ${ }^{71} \mathrm{Ga}(1.65 \mathrm{G}) .{ }^{11 \mathrm{e}}$ These values (see Table 3) contrast sharply with the estimated HFCCs for $\mathbf{6}-\mathbf{G a}^{\mathbf{D i p p}} \mathbf{I},{ }^{11 \mathrm{~d}, \mathrm{~h}}$ for which a significantly larger gallium coupling $(\approx 25 \mathrm{G})$ is thought to exist; the magnitude of the gallium hyperfine coupling in $\mathbf{6 - G a} \mathbf{G i p p}_{\mathbf{I}}$ has recently been confirmed with ENDOR measurements. ${ }^{11 \mathrm{~h}}$ The estimated ${ }^{1} \mathrm{H}$ couplings $(1.4 \mathrm{G})$ in $\mathbf{6}-\mathbf{G a}^{\mathbf{t} \mathbf{B u}_{\mathbf{I}}}$ are also anomalously low and well out of the range typically observed for DAB centred radicals $(5-7 \mathrm{G})^{7-11}$. 
At the same time as $\mathbf{6}-\mathbf{G a}^{\mathbf{t B u}} \mathbf{I}$, the aluminium analogue [(Dipp-DAB)AlI $]^{\bullet}(\mathbf{6}$ $\mathbf{A l}^{\text {Dipp }}$ I) was also reported and characterized by both X-ray crystallography and EPR spectroscopy (Table 3). ${ }^{11 \mathrm{e}}$ The width of the poorly resolved EPR spectrum of $\mathbf{6 - A l ^ { \mathrm { Dipp } }} \mathbf{I}_{\mathbf{I}}$ is similar to that of $\mathbf{6}-\mathbf{G a}^{\mathbf{t B u}} \mathbf{I}$, but a significantly larger ${ }^{1} \mathrm{H}$ coupling $(5.95 \mathrm{G})$ is believed to

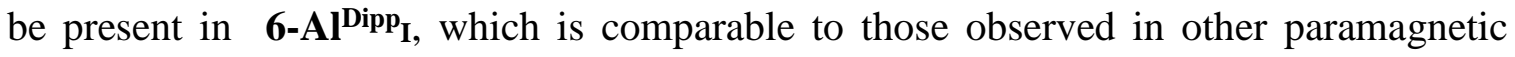
DAB complexes. Extremely small couplings to both the ${ }^{27} \mathrm{Al}(2.85 \mathrm{G})$ and ${ }^{127} \mathrm{I}(0.4 \mathrm{G})$ nuclei were also detected in the EPR spectrum of $\mathbf{6 - A l} \mathbf{A p p}^{\text {Dip }}$; the large $3.5 \mathrm{G}$ line width observed for 6-Al ${ }^{\text {Dipp }}$ I renders these assignments somewhat speculative. However, the simple general appearance of the spectrum (nine lines) and the relatively small spectral width clearly rule out the possibility of large couplings to any high-spin nuclei such as ${ }^{27} \mathrm{Al}$ and ${ }^{127} \mathrm{I}$.

More recently, the indium complex [(Dipp-DAB) $\left.\mathrm{InCl}_{2}\right]^{\bullet}\left(\mathbf{6}^{-\mathbf{I n}^{\mathrm{Dipp}}} \mathbf{C l}\right)$ has been isolated in low yield $(<5 \%)$ from the reaction of [(Dipp-DAB $\left.) \mathrm{Li}_{2}\right]$ with $\mathrm{InCl} ;{ }^{11 \mathrm{~h}}$ the $\mathrm{EPR}$ spectrum of 6-In ${ }^{\text {Dipp }} \mathbf{C l}$ is clearly dominated by a large HFCC to the indium atom $(26.1 \mathrm{G})$. Though accurate values for the ${ }^{1} \mathrm{H}$ and ${ }^{14} \mathrm{~N}$ HFCCs could not be extracted due to the exceptionally broad nature of the spectral lines (line width $\approx 20 \mathrm{G}$ ), they have been estimated at approximately $5 \mathrm{G}$ each, which contrasts with the HFCCs assigned for 6$\mathbf{G a}^{\mathbf{t B u}} \mathbf{I}$, but is consistent with those observed for other DAB radical complexes, including 6-Al ${ }^{\text {Dipp }}$ I and 6-Ga ${ }^{\text {Dipp }}$ I. The ${ }^{35,37} \mathrm{Cl}$ HFCCs are unresolved in the experimental spectrum. In light of the conflicting HFCCs reported for complexes of types $\mathbf{6}-\mathbf{M}^{\mathbf{R}} \mathbf{x}$, DFT calculations have now been carried out on a range of these systems, examining the effect of altering the halogen atom, the DAB nitrogen substituents, and the identity of the group 13 element on the expected HFCCs for these radicals. The calculated metrical parameters 
(see supplementary information) are in good agreement with the structural data obtained from single crystal X-ray diffraction experiments. ${ }^{11, e, h}$ The largest discrepancies are observed for the indium system $6-\mathbf{I n}^{\mathbf{P h}} \mathbf{C l} / \mathbf{6}-\mathbf{I n}^{\text {Dipp }} \mathbf{C l}$ due to the presence of a molecule of THF coordinated to the In atom of $\mathbf{6}-\mathbf{I n}^{\text {Dipp }} \mathbf{C l}$ which was not included in the calculated structure of $6-\mathbf{I n}^{\mathrm{Ph}}{ }{ }^{11 \mathrm{~h}}$

The SOMOs of the monocyclic systems $\mathbf{6}-\mathbf{M}^{\mathbf{R}} \mathbf{x}$ are nearly identical, and are similar to those of the spirocyclic radicals $\mathbf{3}-\mathbf{M}^{\mathbf{R}}$. The calculated HFCCs for $\mathbf{6}-\mathbf{A l}^{\mathbf{P h}} \mathbf{I}$, $\mathbf{6}$ $\mathbf{G a}^{\mathrm{tBu}} \mathbf{I}, \mathbf{6}-\mathbf{G a}^{\mathrm{Ph}} \mathbf{I}$, and 6-In ${ }^{\mathrm{Ph}} \mathrm{Cl}$ are compiled in Table 3; the values for other derivatives of $\mathbf{6}-\mathbf{M}^{\mathbf{R}} \mathbf{X}$ are included as supplementary information. Focusing on the aluminium systems 6-Al ${ }^{\mathbf{R}} \mathbf{x}$, it is noted that the halogen HFCCs exhibit only a small dependence on the identity of the R-group, and that the magnitudes of the ${ }^{1} \mathrm{H}$ and ${ }^{14} \mathrm{~N}$ HFCCs remain essentially unchanged throughout this series (see supplementary information). The absolute value of the aluminium HFCC for these monocycles is predicted to be slightly larger $(8 \mathrm{G})$ than the corresponding coupling in the spirocycles $\mathbf{3}-\mathbf{A} \mathbf{l}^{\mathbf{R}}$, while the ranges of ${ }^{1} \mathrm{H}(6-7 \mathrm{G})$ and ${ }^{14} \mathrm{~N}(3-4 \mathrm{G}) \mathrm{HFCCs}$ for $\mathbf{6}-\mathbf{A l}^{\mathbf{R}} \mathbf{x}$ are comparable to those of $\mathbf{3}-\mathbf{A l} \mathbf{l}^{\mathbf{R}}$. Though the halogen atoms make only a minor contribution to the SOMO, relatively large (6-10 G) hyperfine couplings are predicted to ${ }^{19} \mathrm{~F},{ }^{79,81} \mathrm{Br}$, and ${ }^{127} \mathrm{I}$ nuclei due their large gyromagnetic ratios. ${ }^{16}$ The sizes of these HFCCs are predicted to increase slightly with increasing size of the alkyl substituent; intermediate values were calculated for the aromatic derivatives $\mathbf{6 - A \mathbf { A } ^ { \mathbf { P h } }} \mathbf{x}$ due to the more electron-withdrawing nature of their phenyl rings. In the light of controversy surrounding the assignment of a ${ }^{127} \mathrm{I}$ HFCC in compounds 6-Al ${ }^{\text {Dipp }} \mathbf{I}, \mathbf{6}-\mathbf{G a}^{\mathbf{t B u}} \mathbf{I}$, and 6-Ga $\mathbf{G}^{\text {Dipp }} \mathbf{I},{ }^{11 \mathrm{~d}, \mathrm{~h}}$ these results are of especial import. 
The calculated ${ }^{1} \mathrm{H},{ }^{14} \mathrm{~N}$, and halogen HFCCs for the gallium $\mathbf{6 - G} \mathbf{G}^{\mathbf{R}} \mathbf{x}$ and indium 6-In ${ }^{\mathbf{R}} \mathbf{x}$ systems are consistent with those predicted and discussed for $\mathbf{6}-\mathbf{A l}^{\mathbf{R}} \mathbf{x}$ above. The couplings to the central metals gallium $(\approx 25 \mathrm{G})$ and indium $(\approx 35 \mathrm{G})$ are larger than the HFCCs predicted for the aluminium compounds partially due to the larger gyromagnetic ratios of these heavier isotopes. ${ }^{16}$ The calculated data for $\mathbf{6}-\mathbf{M}^{\mathbf{R}} \mathbf{x}$ (see supplementary information) show that the identity of the halogen atom and the R-group have only very small influence to the HFCC to the central metal; the numerical values remain fairly constant throughout the series and no anomalously low couplings are observed for any of the compounds.

The calculated HFCCs for systems $\mathbf{6}-\mathbf{A l}^{\mathbf{R}} \mathbf{I}$ and $\mathbf{6}-\mathbf{G a}^{\mathbf{R}} \mathbf{I}$ clearly imply the presence of approximately $10 \mathrm{G}$ iodine couplings in all compounds (see supplementary information). While such large values have previously been considered impossible (vide supra $),{ }^{11 \mathrm{e}, \mathrm{g}, \mathrm{h}}$ we have recently shown that the EPR spectra of the structurally related systems $\left\{\left({ }^{\mathrm{t}} \mathrm{Bu}-\mathrm{DAB}\right) \mathrm{Ga}\left[\mathrm{Pn}\left(\mathrm{SiMe}_{3}\right)_{2}\right][\mathrm{I}]\right\}^{\bullet}(\mathrm{Pn}=\mathrm{N}, \mathrm{P}, \mathrm{As})^{11 \mathrm{~g}}$ have been misinterpreted in the past and that these compounds in fact display ${ }^{127} \mathrm{I}$ couplings as large as $20 \mathrm{G}$; the analogous dipnictogen species $\left\{\left({ }^{\mathrm{t}} \mathrm{Bu}-\mathrm{DAB}\right) \mathrm{Ga}\left[\mathrm{Pn}\left(\mathrm{SiMe}_{3}\right)_{2}\right]_{2}\right\}^{\bullet}(\mathrm{Pn}=\mathrm{P}, \mathrm{As})^{11 \mathrm{~g}}$ also exhibit approximately $10 \mathrm{G}$ couplings to the remote Pn nuclei. ${ }^{18}$ In addition, EPR studies on the isoelectronic zinc systems $\left\{\left[\left({ }^{\mathrm{t}} \mathrm{Bu}-\mathrm{DAB}\right) \mathrm{ZnX}_{2}\right]^{-}\right\}^{\bullet}(\mathrm{X}=\mathrm{Cl}, \mathrm{Br})$, which produce well-resolved spectra, have demonstrated that the bromine derivative displays an approximately $9 \mathrm{G}$ coupling to the heavy halogen ${ }^{79,81} \mathrm{Br} .{ }^{10} \mathrm{In}$ light of these experimental data and the present computational analyses, it appears highly unlikely that the group 13 systems 6- $\mathbf{M}^{\mathbf{R}_{\mathbf{I}}}$ would exhibit such small HFCCs to iodine as has been inferred previously. $^{11 \mathrm{e}, \mathrm{g}, \mathrm{h}}$ 
A comparison between the calculated HFCCs for the gallium species $\mathbf{6 - G a} \mathbf{R}_{\mathbf{I}}$ and the experimentally gleaned HFCCs for $\mathbf{6}-\mathbf{G a}^{\mathbf{t B u}} \mathbf{I}{ }^{11 \mathrm{e}}$ and $\mathbf{6}-\mathbf{G a}^{\mathbf{D i p p}} \mathbf{I}{ }^{11 \mathrm{~d}, \mathrm{~h}}$ reveals a strong correlation between the calculated values for $\mathbf{6 - G a} \mathbf{G h}_{\mathbf{I}}$ and those estimated based on the EPR spectrum of the closely related 6-Ga ${ }^{\text {Dipp }_{I}}$ (Table 3). The experimental and calculated ${ }^{69} \mathrm{Ga}$ hyperfine couplings differ by only $2 \mathrm{G}$; this agreement is excellent considering the difficulties associated with the accurate modelling of spin-polarization effects. As noted before, there has been some controversy about the size of the iodine coupling in $\mathbf{6}-\mathbf{G a}^{\text {Dipp }} \mathbf{I}$ and two significantly different values, $1.5 \mathrm{G}$ and $8 \mathrm{G}$, have been suggested. ${ }^{11 \mathrm{~d}, \mathrm{~h}}$ The present work lends strong support for the latter interpretation as the calculated ${ }^{127} \mathbf{I}$ hyperfine coupling for $\mathbf{6 - G a} \mathbf{G i p p}_{\mathbf{I}}$ is $8.9 \mathrm{G}$. While calculations have predicted the ${ }^{1} \mathrm{H}$ HFCC to be larger than the ${ }^{14} \mathrm{~N}$ HFCC, the reverse has been determined experimentally. ${ }^{11 \mathrm{~d}, \mathrm{~h}}$ This can be attributed to the tendency of the chosen theoretical method to overestimate ${ }^{1} \mathrm{H}$ couplings while underestimating the ${ }^{14} \mathrm{~N}$ HFCC which was noted and discussed above. It is also possible that the experimental ${ }^{14} \mathrm{~N}$ HFCCs, which are only estimated values, are slightly erroneous due the poorly resolved nature of the experimental EPR spectrum.

Conversely, little or no correlation can be made between the calculated and experimental HFCCs for the ${ }^{t} \mathrm{Bu}-\mathrm{DAB}$ complex $\mathbf{6 - G} \mathbf{G a}^{\mathbf{t B u}} \mathbf{I}$ (Table 3). While the calculated data indicate that the ${ }^{69} \mathrm{Ga},{ }^{1} \mathrm{H}$, and ${ }^{127} \mathrm{I}$ HFCCs of $\mathbf{6}-\mathbf{G a}^{\mathbf{t B u}} \mathbf{I}$ should be quite close to those

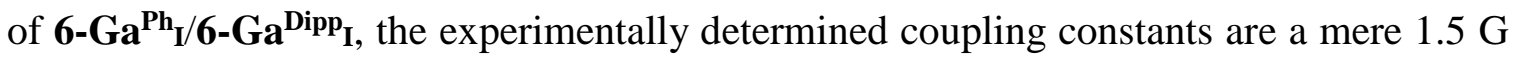
each (!). ${ }^{11 \mathrm{e}}$ At the present time, no definite explanation for these anomalous values can be offered, other than to note that the experimentally determined HFCCs and g-value for 6$\mathbf{G a}^{\mathbf{t B u}} \mathbf{I}$ are surprisingly similar to those reported for the dimeric diradical 


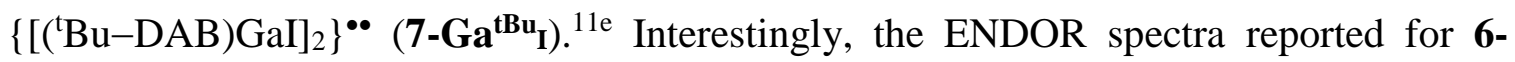
$\mathbf{G a}^{\mathrm{tBu}}{ }_{\mathbf{I}}$ and $\mathbf{7 -} \mathbf{G a}^{\mathbf{t B u}}{ }_{I}$ are also virtually identical. ${ }^{1 \mathrm{~h}}$ It is possible that compounds $\mathbf{6}-\mathbf{G a}^{\mathbf{t B u}} \mathbf{I}$ and 7-Ga ${ }^{\mathrm{tBu}} \mathbf{I}$, which are the minor and major products, respectively, of the same reaction, undergo various processes (such as disproportionation) in solution which equilibrate to yield significant amounts of the paramagnetic species that has been detected by EPR spectroscopy. We will resume to this topic in more detail in the next section discussing the dimeric diradicals 7-M $\mathbf{M}^{\mathbf{R}} \mathbf{X}$.

In the case of the aluminium systems $\mathbf{6}-\mathbf{A l}^{\mathbf{R}} \mathbf{I}$, the HFCCs estimated based on the experimental EPR spectrum of $\mathbf{6}-\mathbf{A l}^{\mathbf{D i p p}_{\mathbf{I}}}{ }^{11 \mathrm{e}}$ are not entirely consistent with those

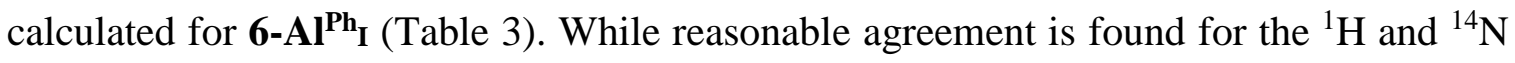
couplings, the observed ${ }^{27} \mathrm{Al}$ and ${ }^{127} \mathrm{I}$ HFCCs are again considerably smaller than the predicted values. As $\mathbf{6}-\mathbf{A l}^{\mathbf{D i p p}} \mathbf{I}$ is expected to display a significant ${ }^{127}$ I coupling, it seems reasonable to suggest that the species characterized in solution by EPR spectroscopy is not the same radical $\mathbf{6}-\mathbf{A l}^{\mathbf{D i p p}_{\mathbf{I}}}$ that was identified in the solid state by X-ray crystallography. This conclusion is further supported by the experimental observation that the reduction of 6-Al ${ }^{\text {Dipp }}$ I with excess potassium in THF does not lead to the $\mathrm{M}^{\mathrm{I}}$ carbene analogue $[(\mathrm{Dipp}-\mathrm{DAB}) \mathrm{Al}:]^{-}$, whereas the same reaction with $\mathbf{6}-\mathbf{G a}^{\mathbf{D i p p}_{\mathbf{I}}}$ proceeds as expected and gives the potassium salt of $[(\text { Dipp-DAB }) \mathrm{Ga}:]^{-} .{ }^{11 \mathrm{e}}$ In addition, the ENDOR

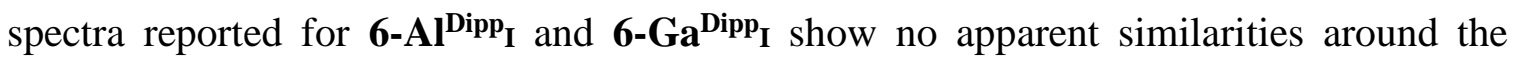
proton Larmor frequency. ${ }^{11 \mathrm{~h}}$

The identity of the chemical species giving the EPR spectrum assigned to 6-

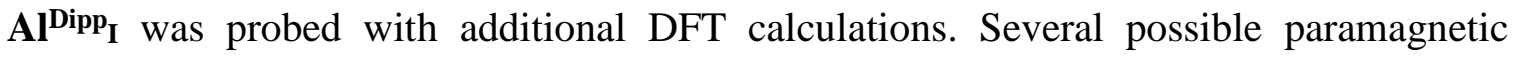
systems were examined, including $\left\{[(\mathrm{R}-\mathrm{DAB}) \mathrm{Al}]^{-}\right\}^{\bullet}, \quad\left\{[(\mathrm{R}-\mathrm{DAB}) \mathrm{AlI}]^{-}\right\}^{\bullet}, \quad$ and 
$\left\{[(\mathrm{R}-\mathrm{DAB}) \mathrm{AlI}]^{+}\right\}^{\bullet}$. It was found that the calculated HFCCs for any of these radicals do not accurately reproduce the simple nine line EPR spectrum reported for $\mathbf{6}-\mathbf{A l}^{\text {Dipp }}{ }^{\text {I. Thus, }}$, we cannot at this stage provide a definite identification of this paramagnetic species, but suggest that further experimental work is in order to gain a better understanding of this system.

While the experimental ${ }^{11 \mathrm{~h}}$ and calculated HFCCs for the indium complexes 6$\mathbf{I n}^{\text {Dipp }} \mathbf{C l}$ and 6-In ${ }^{\mathbf{P h}} \mathbf{C l}$ are in excellent agreement with each other, it must be noted that the EPR spectrum of 6-In ${ }^{\text {Dipp }} \mathbf{C l}$ has such broad lines that it can be simulated in a number of different ways, using a range $(0-5 \mathrm{G})$ of both ${ }^{1} \mathrm{H}$ and ${ }^{14} \mathrm{~N}$ HFCCs and adjusting the line width parameter of the simulation program appropriately. The broad line shape also masks any information regarding the ${ }^{35,37} \mathrm{Cl} \mathrm{HFCC}$ as these couplings are expected to be approximately $1 \mathrm{G}$ (Table 3). In consequence, the accuracy of the experimentally derived

${ }^{1} \mathrm{H}$ and ${ }^{14} \mathrm{~N}$ HFCCs should not be overestimated. However, as the ${ }^{115} \mathrm{In}$ coupling can readily be extracted from the experimental EPR spectrum of $\mathbf{6}-\mathbf{I n}^{\mathrm{Dipp}} \mathbf{C l}$, a comparison of this value $(27 \mathrm{G})$ with the calculated $\operatorname{HFCC}(-33.7 \mathrm{G})$ is much more valid: though the agreement is not exact, the fit is reasonable.

\section{Dimeric group 13 diazabutadiene diradicals}

The first complex of a group 13 element with not one but two paramagnetic DAB ligands was reported recently. ${ }^{11 \mathrm{f}}$ This dimeric diradical consists of two [(Dipp-DAB)InCl] fragments which dimerize via indium-indium bond formation to yield the indium(II) complex $\left\{[(\mathrm{Dipp}-\mathrm{DAB}) \mathrm{InCl}]_{2}\right\}^{\bullet \bullet}\left(\mathbf{7}-\mathbf{I n}^{\mathrm{Dipp}} \mathbf{C l}\right)$. Red crystals of this diradical were recovered as a minor product (12\%) of a disproportionation reaction between $\mathrm{InCl}$ and 
the neutral Dipp-DAB ligand. Still more recently, three gallium analogues of this complex have been isolated as products of complex reaction mixtures and characterized by X-ray crystallography. ${ }^{11 \mathrm{e}, \mathrm{h}}$ The two aromatic derivatives $\left\{[(\mathrm{Dipp}-\mathrm{DAB}) \mathrm{GaX}]_{2}\right\}^{\bullet \bullet}(\mathrm{X}=$ Br, 7-Ga $\left.{ }^{\text {Dipp }} \mathbf{B r} ; \mathbf{X}=\mathrm{I}, \mathbf{7 - G a} \mathbf{D i p p}_{\mathbf{I}}\right)^{11 \mathrm{~h}}$ are isostructural with $\mathbf{7 - \mathbf { I n } ^ { \text { Dipp } }} \mathbf{C l}$, with the halogen atoms anti to one another; for the alkyl-substituted complex $\left\{\left[\left({ }^{\mathrm{t}} \mathrm{Bu}-\mathrm{DAB}\right) \mathrm{GaI}\right]_{2}\right\}^{\bullet \bullet}(\mathbf{7}-$ $\left.\mathbf{G a}^{\mathbf{t B u}} \mathbf{I}\right),{ }^{11 \mathrm{e}}$ the iodine atoms are in a staggered conformation with a IGaGaI dihedral angle of $73^{\circ}$. This difference in geometry appears to result in massive changes to the electronic structures of 7-Ga ${ }^{\mathbf{t B u}} \mathbf{x}$ and 7-Ga'bipp $\mathbf{x}$, with a ${ }^{69}$ Ga HFCC of 1.20 G reported for $\mathbf{7 - G} \mathbf{G}^{\mathbf{t B u}} \mathbf{I}$, while substantially larger values of $22.5 \mathrm{G}$ and $17.0 \mathrm{G}$ are observed for $\mathbf{7 - \mathbf { G a } ^ { \text { Dipp } }} \mathbf{B r}$ and 7$\mathbf{G a}^{\text {Dipp }} \mathbf{I}$, respectively. ${ }^{11 \mathrm{e}, \mathrm{h}}$

The reason for the experimentally observed differences between the solid state structures of $\mathbf{7 - G a}{ }^{\mathbf{t B u}} \mathbf{x}$ and $\mathbf{7 - G} \mathbf{a}^{\text {Dipp }} \mathbf{x}$, and the resultant alteration in the magnitude of the gallium HFCC was probed using DFT calculations. For $\mathbf{7 - G a}{ }^{\mathbf{R}} \mathbf{x}\left(\mathrm{R}=\mathrm{H}, \mathrm{Me},{ }^{\mathrm{t}} \mathrm{Bu}, \mathrm{Ph}\right)$, the global energy minimum occurs when the two halogen atoms are in a staggered conformation, in agreement with the experimentally determined structure of $\mathbf{7 - G} \mathbf{a}^{\mathbf{t B u}} \mathbf{I}$. Calculations were done varying the identity of the halogen atom by employing two fluorine, chlorine, bromine, or iodine atoms; the identity of the halogen atoms was not observed to affect the predicted geometry of the molecule. The calculated and experimentally ${ }^{11 \mathrm{e}, \mathrm{h}}$ determined metrical parameters for staggered-7-Ga $\mathbf{a}^{\mathbf{t B u}} \mathbf{I}$, and anti-7$\mathbf{G a}^{\mathbf{P h}}{ }_{\mathbf{B r}, \mathbf{I} / \text { anti-7-Ga }^{\mathrm{Dipp}}} \mathbf{B r}_{\mathbf{I}, \mathbf{I}}$ are compiled in supplementary information.

A distinct anomaly is seen for the $\mathrm{Ga}-\mathrm{Ga}$ bond length in anti-7-Ga ${ }^{\mathbf{P h}} \mathbf{I} /$ anti-7Ga $^{\text {Dipp }}$ I: the calculated bond length for the phenyl derivative is $2.461 \AA$ while the experimental value for the Dipp system is considerable larger at $2.575 \AA^{11 \mathrm{~h}}$ At first, it is 
tempting to assign this discrepancy to the larger steric bulk of the Dipp substituent compared to the phenyl. However, the calculated and experimental ${ }^{11 \mathrm{~h}} \mathrm{Ga}-\mathrm{Ga}$ bond lengths for the related bromine pair anti-7-Ga ${ }^{\mathbf{P h}}{ }_{\mathbf{B r}} /$ anti-7-Ga $^{\mathbf{D i p p}} \mathbf{B r}$ are in excellent agreement: $2.454 \AA$ and $2.466 \AA$ for anti-7-Ga $^{\mathbf{P h}}{ }_{\mathbf{B r}}$ and anti-7-Ga $^{\mathrm{Dipp}} \mathbf{B r}$, respectively.

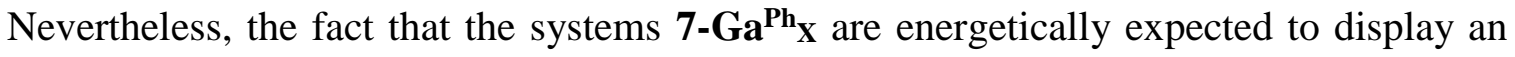
approximately staggered orientation of their two $\mathrm{X}$ atoms, while the closely related complexes 7-Ga ${ }^{\text {Dipp }}{ }_{\text {Br }}$ and $\mathbf{7 - G a} \mathbf{G i p p}_{\mathbf{I}}$ are both known to exist in the anti conformation is believed to be due to the large size of the bulky Dipp substituents: the steric repulsions between the Dipp groups render the anti geometry more stable. It should also be noted that the staggered conformations of $\mathbf{7 - \mathbf { G a } ^ { \mathbf { P h } }} \mathbf{x}$ are calculated to be only about $20-30 \mathrm{~kJ}$ $\mathrm{mol}^{-1}$ more stable than the anti isomers.

Similar calculations were done for the aluminium and indium analogues $\left\{[(\mathrm{R}-\mathrm{DAB}) \mathrm{AlX}]_{2}\right\}^{\bullet \bullet}\left(\mathbf{7 - A l ^ { \mathbf { R } }} \mathbf{x}\right)$ and $\left\{[(\mathrm{R}-\mathrm{DAB}) \operatorname{InX}]_{2}\right\}^{\bullet \bullet}\left(\mathbf{7}-\mathbf{I n}^{\mathbf{R}} \mathbf{x}\right)$. In all cases, regardless of the identity of the halogen atoms and substituents R, the lowest-energy geometries were found to be those where an approximately staggered conformation of the DAB ligands was observed. Though the aluminium complexes $\mathbf{7 - A l ^ { \mathbf { R } }} \mathbf{\mathbf { X }}$ are as yet unknown, the indium species 7-In ${ }^{\text {Dipp }} \mathbf{C l}$ has been characterized in the solid state and is known to exist in the anti conformation, likely due to the presence of a bulky Dipp groups on each nitrogen atom of the DAB ligands. ${ }^{11 \mathrm{f}}$ The calculated and experimentally ${ }^{11 \mathrm{f}}$ determined metrical parameters for anti-7-In ${ }^{\mathbf{P h}} \mathbf{C l} /$ anti-7-In ${ }^{\text {Dipp }} \mathrm{Cl}$ pair are included in supplementary information.

The nature of the singly occupied molecular orbitals of the staggered isomers of 7-M $\mathbf{M}^{\mathbf{R}} \mathbf{x}$ were found to exhibit only minimal dependence on the identity of the group 13 
atom, the halogen atoms, and the substituents on the DAB nitrogen atoms. As seen earlier for radicals 3-M $\mathbf{M}^{\mathbf{R}}$ and $\mathbf{6}-\mathbf{M}^{\mathbf{R}} \mathbf{x}$, the SOMOs are mostly ligand centred. Only one of the two SOMOs is found to be bonding between the two $[(\mathrm{R}-\mathrm{DAB}) \mathrm{MX}]^{\bullet}$ units; the bonding contribution is visible only when relatively small isosurface values are probed. The SOMOs of the anti isomers of $\mathbf{7 -}-\mathbf{M}^{\mathbf{R}} \mathbf{x}$ are similarly independent of the identities of the group 13 atom, halogen atoms, and the R-group. The orbitals are ligand centred and very similar to what is observed for the staggered isomers. Interestingly, the SOMO of the anti isomer shows a bonding interaction through the $\mathrm{M}-\mathrm{M}$ linkage only at exceptionally small isosurface values. This not only results in somewhat elongated $\mathrm{M}-\mathrm{M}$ bonds in the anti isomers compared to the staggered, but also rationalizes why the staggered orientation is slightly lower in energy.

An examination of the SOMOs of systems $\mathbf{7}-\mathbf{M}^{\mathbf{R}} \mathbf{x}$ reveals that they should be disjoint diradicals with little or no exchange interaction between the two paramagnetic centres as the two MOs can be localized on separate groups of atoms; hence, doublet-type EPR spectra are predicted. For the staggered isomers, each unpaired electron is expected to interact with one group 13 atom, one halogen atom, two inequivalent ${ }^{14} \mathrm{~N}$ atoms and two inequivalent ${ }^{1} \mathrm{H}$ nuclei due to the $C_{2}$ symmetry of the molecules. The two ${ }^{14} \mathrm{~N}$ HFCCs are similar in all these systems and within a given species do not differ from each other by more than $0.5 \mathrm{G}$ (see supplementary information). These couplings are smaller than those predicted for the monoradicals $3-\mathbf{M}^{\mathbf{R}}$ and $\mathbf{6}-\mathbf{M}^{\mathbf{R}} \mathbf{x}$, with an approximate value of $2 \mathrm{G}$. Likewise, the ${ }^{1} \mathrm{H}$ coupling constants are within $0.5 \mathrm{G}$ of each other in a given derivative

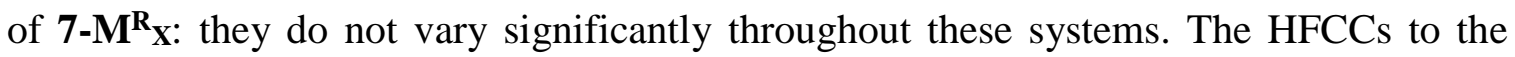
halogen atoms are consistent with the relative sizes of the isotropic hyperfine constants of 
these nuclei: the largest predicted couplings are to fluorine $(\approx 12 \mathrm{G})$ and iodine $(\approx 10 \mathrm{G})$, with smaller HFCCs to bromine $(\approx 8 \mathrm{G})$ and chlorine $(\approx 2 \mathrm{G})$. The calculated iodine HFCCs are considerably larger than expected based on the experimental information available ${ }^{11 \text { e,f,h }}$ however, both our calculations for $\mathbf{6}-\mathbf{M}^{\mathbf{R}} \mathbf{I}$ and for some related galliumpnictogen systems ${ }^{18}$ have clearly indicated that accurate ${ }^{127}$ I HFCCs are generated by the theoretical method used.

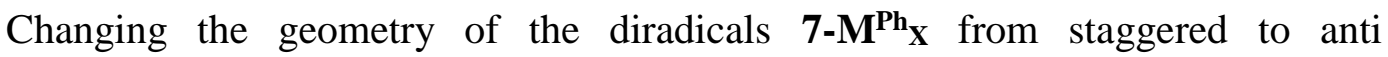
conformation has a distinct effect on the calculated magnitudes of the HFCCs to the group 13 nuclei (see supplementary information). In the case of gallium, the ${ }^{69} \mathrm{Ga} \mathrm{HFCC}$ decreases 3-5 G, depending on the identity of the halogen atoms, while the indium HFCCs drop approximately $6 \mathrm{G}$. The effect of geometry to the ${ }^{1} \mathrm{H},{ }^{14} \mathrm{~N}$, and halogen HFCCs is markedly smaller and generally on the order of half a Gauss.

Looking more closely at a specific diradical system, no correlation between the HFCCs inferred from the experimental EPR spectrum of $\mathbf{7 - G a} \mathbf{D i p p}_{\mathbf{I}}$ and the calculated

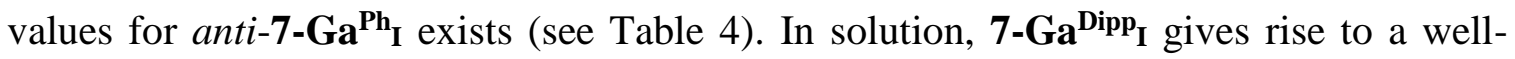
resolved EPR spectrum such that it is possible to extract accurate values for not only the ${ }^{69} \mathrm{Ga}$ HFCC, but also the ${ }^{1} \mathrm{H}$ and ${ }^{14} \mathrm{~N}$ HFCCs. ${ }^{11 \mathrm{~h}}$ However, very poor agreement is observed between the calculated and experimentally determined HFCCs: the predicted ${ }^{69} \mathrm{Ga} \mathrm{HFCC}$ is $3.6 \mathrm{G}$, while the experimental value is $17.0 \mathrm{G}$, and both the ${ }^{1} \mathrm{H}$ and ${ }^{14} \mathrm{~N}$ HFCCs are approximately $3 \mathrm{G}$ higher than the calculated values. Though the predicted ${ }^{127} \mathrm{I}$ HFCC is $6.6 \mathrm{G}$ - a value which should be clearly visible in the EPR spectrum - the available experimental data shows no indication of such a large iodine coupling. In fact, a closer look to the experimental data reveals that both the EPR and ENDOR spectra of 7- 


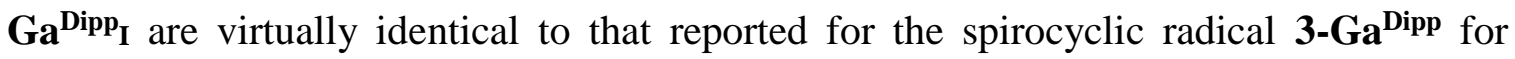
which the calculations reproduced the experimental HFCCs well; ${ }^{1 \mathrm{~h}}$ the reported g-values of the radicals 7-Ga ${ }^{\text {Dipp }}$ I and $\mathbf{3 - G a} \mathbf{G}^{\text {Dipp }}$ are also the same (2.0032). Thus, the experimental

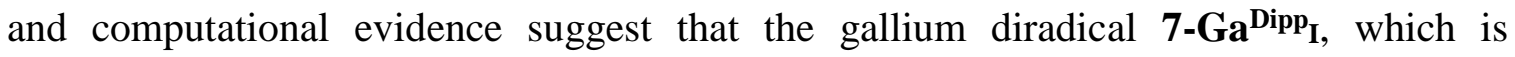
obtained as a minor product from the reaction between a Dipp-DAB ligand and "Gal", undergoes a rearrangement (disproportionation) in solution to yield the well-known, stable, spirocyclic radical 3-GaDipp.

Additional evidence which supports the above hypothesis is obtained from the crystal structure of $\mathbf{7 - \mathbf { G a } ^ { \text { Dipp } }}{ }_{\mathbf{I} .}{ }^{1 \mathrm{~h}}$ As noted earlier, the experimental $\mathrm{Ga}-\mathrm{Ga}$ bond length is

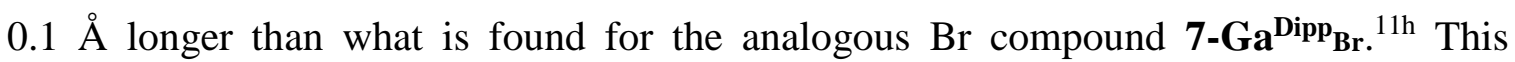

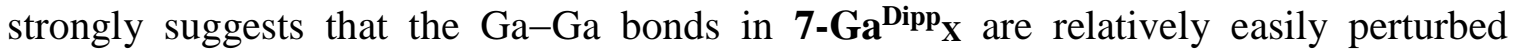
which could facilitate the break-up of the triplet state diradicals in solution. Theoretical calculations for systems $\mathbf{7 - G a}{ }^{\mathbf{P h}} \mathbf{x}$ with elongated $\mathrm{Ga}-\mathrm{Ga}$ bond lengths confirmed this reasoning as an increase of $0.1 \AA$ in bond length was found to raise the total energy of a given compound by only $10 \mathrm{~kJ} \mathrm{~mol}^{-1}$.

To stress the hypothesis even further, reaction energies were calculated at the PBE0/TZVP level of theory for a simple disproportionation reaction giving the expected end product 3-Ga $\mathbf{G}^{\text {Dipp }}$ i.e. $2\left\{[(\mathrm{R}-\mathrm{DAB}) \mathrm{GaI}]_{2}\right\}^{\bullet \bullet} \rightarrow 2\left[(\mathrm{R}-\mathrm{DAB})_{2} \mathrm{Ga}\right]^{\bullet}+\mathrm{Ga}_{2} \mathrm{I}_{4}$. This reaction is found to be vastly endergonic for the $\mathrm{R}=\mathrm{H}$ derivative $\left(\Delta G^{\circ}=160 \mathrm{~kJ} \mathrm{~mol}^{-1}\right)$ but becomes more favourable as the size of the substituent $\mathrm{R}$ increases; for the $\mathrm{R}=\mathrm{Ph}$ derivative, the reaction is essentially thermoneutral $\left(\Delta G^{\circ}=8 \mathrm{~kJ} \mathrm{~mol}^{-1}\right)$. Although we did not repeat the calculations using the experimental Dipp substituted systems due to their large computational cost, it feels reasonable to expect that the energy for that reaction is 
close to, or possibly even less than, the value calculated utilizing the Ph derivatives. We also note that the above disproportionation reaction can be further driven to the exergonic side by subsequent transformations of $\mathrm{Ga}_{2} \mathrm{I}_{4}$ to a mixture of gallium sub-iodides having the Ga metal in either +3 or +1 oxidation state $c . f$. Green's "GaI". ${ }^{19}$ Thus, it seems more than plausible that the diradical $\mathbf{7 - G a} \mathbf{D i p p}_{\mathbf{I}}$ undergoes a variety of reactions in solution, yielding the spirocyclic radical 3-Ga ${ }^{\text {Dipp }}$ that has been observed by EPR and ENDOR spectroscopies. ${ }^{11 \mathrm{~h}}$ Unfortunately, no UV-vis data has been reported for either 7-Ga ${ }^{\text {Dipp }}$ I or 3-Ga ${ }^{\text {Dipp }}$ which could be used to either confirm or refute this hypothesis.

The lone bromine-containing derivative $\mathbf{7 - G a}{ }^{\text {Dipp }}$ Br gives rise to a solution EPR spectrum consisting of a broad resonance $(\approx 200 \mathrm{G})$ with unresolved hyperfine couplings. ${ }^{1 \mathrm{~h}}$ Due to the poor resolution of the spectrum, the experimentally derived HFCCs (Table 4) are only estimated values: in fact, attempts to simulate the experimental EPR spectrum using the reported HFCCs do not accurately reproduce the shape or width of the experimental spectrum (see Figure 2a). ${ }^{20}$ Similarly, when the calculated HFCCs are employed, the simulated EPR spectrum is also considerable narrower than the experimental (not shown). The broad EPR spectrum observed for $\mathbf{7 - G a a ^ { \text { Dipp } }} \mathbf{B r}$ clearly indicates a large ${ }^{69,71} \mathrm{Ga}$ coupling of approximately $20-25 \mathrm{G}$ in size. Thus, the experimentally obtained solution EPR spectrum is not, in fact, produced by $\mathbf{7 - G a} \mathbf{a}^{\text {Dipp }} \mathbf{B r}$, as its calculated HFCCs show only a very minute coupling to the group 13 metal (see Table 4). Based on the above analysis for $\mathbf{7 - G a} \mathbf{D i p p}_{\mathbf{I}}$, it is tempting to propose that the bromine derivative, like its iodine analogue, undergoes disproportionation in solution. The end product cannot, however, be the spirocyclic monoradical 3-Ga'Dipp as it produces an EPR spectrum which is markedly different than that observed for $\mathbf{7 - G a} \mathbf{G i p p}_{\mathbf{B r} \text {. }}$ 
To shed light upon this matter, the reported EPR spectrum of $\mathbf{7 - G a} \mathbf{G i p p}_{\mathbf{B r}}$ was reanalysed. ${ }^{11 \mathrm{~h}}$ The spectrum displays a broad singlet signal with a plethora of fine structure. Upon closer inspection, it was found that the peak distances within the fine structure are approximately constant throughout the whole spectrum. This implies that the paramagnetic species in question displays $\mathrm{a} \approx 6 \mathrm{G}$ HFCC to a high-spin nucleus or to a several nuclei with lower spins (possibly ${ }^{1} \mathrm{H}$ and ${ }^{14} \mathrm{~N}$ ). The broad nature of the signal also implies that more than one large (>10 G) coupling is present. In addition to the large ${ }^{69,71} \mathrm{Ga}$ HFCC, these couplings could well be due to the ${ }^{79,81} \mathrm{Br}$ nuclei if the disproportionation of $\mathbf{7 - \mathbf { G a } ^ { \mathbf { D i p p } }} \mathbf{B r}_{\mathbf{B r}}$ yields, for example, the monocyclic radical

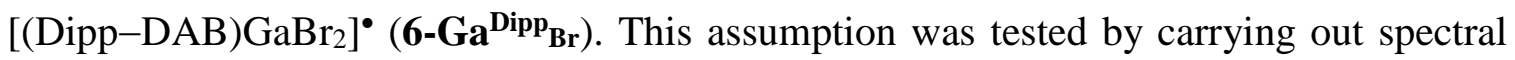
simulations utilizing the calculated HFCCs of $\mathbf{6}-\mathbf{G a}^{\mathbf{D i p p}} \mathbf{B r}$ as a starting point.

The newly simulated ${ }^{20}$ EPR spectrum of $\mathbf{7}-\mathbf{G a}^{\mathbf{D i p p}} \mathbf{B r}$ is shown in Figure $2 \mathrm{~b}$ and is a excellent match with the published EPR spectrum. ${ }^{11 \mathrm{~h}}$ The simulation employs $18 \mathrm{G}$ and $25 \mathrm{G}$ HFCCs to ${ }^{69} \mathrm{Ga}$ and ${ }^{71} \mathrm{Ga}$ isotopes, respectively, $6 \mathrm{G}$ couplings to two ${ }^{1} \mathrm{H}$ and two ${ }^{14} \mathrm{~N}$ nuclei, as well as an appropriate combination of ${ }^{79} \mathrm{Br}(11.0 \mathrm{G})$ and ${ }^{81} \mathrm{Br}(11.9 \mathrm{G})$ couplings to the two halogen centres. These values are in good agreement with the computational results for $\mathbf{6}-\mathbf{G a}^{\mathbf{D i p p}} \mathbf{B r}$ and provide solid evidence that the species present in the EPR spectrum of $\mathbf{7 - G a} \mathbf{G i p p}_{\mathbf{B r}}$ is not the dimeric diradical observed in the solid state but instead the monocyclic radical $\left[(\text { Dipp-DAB }) \mathrm{GaBr}_{2}\right]^{\bullet}$.

Not entirely surprising is the observation that no correlation between the HFCCs

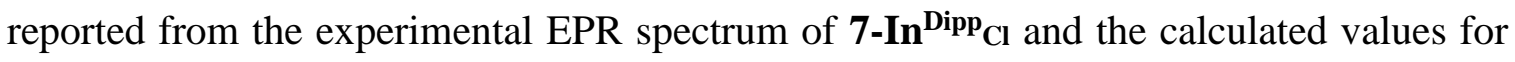
anti-7- $\mathbf{I n}^{\mathrm{Ph}} \mathrm{Cl}$ exists (see Table 4). For example, the reported indium HFCC is $26.2 \mathrm{G}$, while the predicted value is $4.3 \mathrm{G}$; the expected ${ }^{1} \mathrm{H}(-2.6 \mathrm{G})$ and ${ }^{14} \mathrm{~N}(2.2 \mathrm{G}) \mathrm{HFCC}$ are 
both considerable smaller than those cited in the literature. ${ }^{11 \mathrm{f}}$ As noted above, the reported EPR spectrum of $\mathbf{7 - \mathbf { I n } ^ { \text { Dipp } }}{ }_{\mathbf{C l}}$, including its width, g-value, ${ }^{115} \mathrm{In}$ HFCC, and line width, is essentially identical to that reported for the monocyclic monoradical 6In $^{\text {Dipp }}{ }_{\mathbf{C l}}{ }^{1{ }^{1 \mathrm{~h}}}$ In fact the dimeric diradical 7-In ${ }^{\text {Dipp }} \mathbf{C l}$ crystallizes with an equivalent of the neutral Dipp-DAB ligand in its lattice. ${ }^{11 \mathrm{f}}$ Thus, once single crystals of $\mathbf{7 - \mathbf { I n } ^ { \text { Dipp } }}{ }_{\mathbf{C l}}$ are dissolved in solution so as to obtain an EPR spectrum, the two species are free to react, as neutral DAB ligands are readily reduced. Taking into account the tendency of the analogous Dipp substituted gallium systems to undergo disproportionation reactions in solution, it is not difficult to envisage a reaction mechanism whereby the disproportion of 7-In ${ }^{\text {Dipp }} \mathbf{C l}$ in the presence of an equivalent of Dipp-DAB, accompanied by chloride ion transfer, produces the monocyclic radical 6-In ${ }^{\text {Dipp }} \mathbf{C l}$. This would explain both the surprising similarities between the EPR spectra of 6-In $^{\text {Dipp }} \mathbf{C l}$ and $7-\mathbf{I n}^{\text {Dipp }} \mathbf{C l}$, and the discrepancies between the experimentally derived and calculated ${ }^{115} \mathrm{In}$ HFCCs for 7$\mathbf{I n}^{\text {Dipp }} \mathbf{C l}$ and 7-In ${ }^{\mathbf{P h}} \mathbf{C l}$. However, since no definite ${ }^{35,37} \mathrm{Cl}$ couplings have been detected in

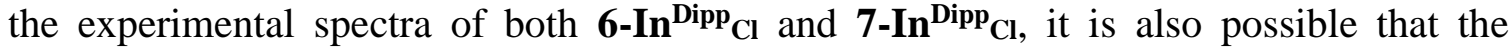
paramagnetic species present in the solution is the spirocyclic monoradical 3-In ${ }^{\text {Dipp }}$ (vide supra). Further experimental data, perhaps in the guise of UV-vis spectra, are needed to fully resolve this issue.

The final compound for which both experimental and calculated data are available is the alkyl derivative 7-Ga ${ }^{\mathbf{t B u}} \mathbf{I}$. As it exists in the staggered conformation in the solid state, ${ }^{11 \mathrm{e}}$ calculations have indicated that it should have a significantly larger ${ }^{69} \mathrm{Ga}$ HFCC (11.2 G) than its Dipp analogues $\mathbf{7 - G a}^{\text {Dipp }} \mathbf{B r}$ and $\mathbf{7 - G ^ { \text { Dipp } }}{ }^{\text {; }}$ conversely, the

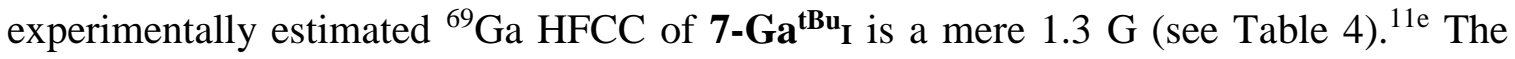


experimental EPR spectrum of 7-Gat $\mathbf{t}^{\mathbf{B} \mathbf{u}_{\mathbf{I}}}$ is very poorly resolved, and has not allowed for accurate determination of the ${ }^{1} \mathrm{H}$ and ${ }^{14} \mathrm{~N}$ HFCCs. As the general features of this spectrum are quite similar to those of the better-resolved spectrum of $\mathbf{6 - G a} \mathbf{G}^{\mathbf{t B u}} \mathbf{I}$ described earlier, the spectrum of 7-Ga ${ }^{\mathbf{t B u}_{\mathbf{I}}}$ was simulated using the same HFCCs, but a larger line width. ${ }^{11 \mathrm{e}}$ Since the g-values of the experimental EPR spectra of $\mathbf{6 - G} \mathbf{G a}^{\mathbf{t B u}} \mathbf{I}(2.0038)$ and $\mathbf{7 - G} \mathbf{a}^{\mathbf{t B u}} \mathbf{I}$ (2.00385) are nearly identical and their EPR (and also ENDOR) spectra can be adequately simulated using the same HFCCs, ${ }^{11 \mathrm{e}, \mathrm{h}}$ it seems probable that the species contributing to the experimental EPR spectrum of $\mathbf{7 - G} \mathbf{G}^{\mathbf{t B u}} \mathbf{I}$ is the same species observed in the EPR spectrum of $\mathbf{6}-\mathbf{G a}^{\mathbf{t B u}} \mathbf{I}$. However, the theoretical calculations reported herein clearly exclude the possibility that this unknown species would be of any of the types observed earlier i.e. a spirocyclic, monocyclic, or a dimeric gallium DAB radical. Thus, we are unable to provide a definite identification for this species. Detailed theoretical

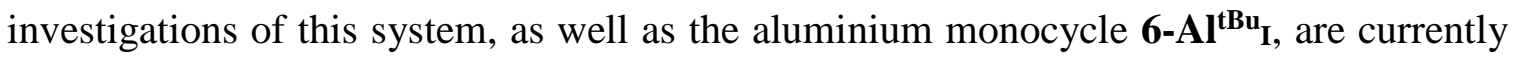
being pursued.

\section{Conclusions}

The electronic structures and the spin density distributions of the group 13 DAB radicals $\left[(\mathrm{R}-\mathrm{DAB})_{2} \mathrm{M}^{\bullet}\left(\mathbf{3}-\mathrm{M}^{\mathbf{R}}\right),\left[(\mathrm{R}-\mathrm{DAB}) \mathrm{MX}_{2}\right]^{\bullet}\left(\mathbf{6}-\mathbf{M}^{\mathbf{R}} \mathbf{x}\right)\right.$, and $\left\{[(\mathrm{R}-\mathrm{DAB}) \mathrm{MX}]_{2}\right\}^{\bullet \bullet}\left(\mathbf{7}-\mathbf{M}^{\mathbf{R}} \mathbf{x}\right)(\mathrm{M}$ $=\mathrm{Al}, \mathrm{Ga}, \mathrm{In} ; \mathrm{X}=\mathrm{F}, \mathrm{Cl}, \mathrm{Br}, \mathrm{I} ; \mathrm{R}=\mathrm{H}, \mathrm{Me},{ }^{\mathrm{t}} \mathrm{Bu}, \mathrm{Ph}$ ) were studied using density functional theory. The calculations accurately reproduce the geometries of all systems and clearly demonstrate that all radicals have qualitatively similar SOMOs with the unpaired electron(s) residing on the diazabutadiene backbone(s). Thus, all compounds are primarily ligand centred $\pi$-radicals which exhibit only relatively weak interactions 
between the unpaired electron and the group 13 and halogen nuclei. The metal, nitrogen, and hydrogen hyperfine couplings were found to be independent of the identity of the Rgroup or the halogen atom. They are, however, dependent on the geometry (staggered vs. anti isomer for $\mathbf{7}-\mathbf{M}^{\mathbf{R}} \mathbf{x}$ ) and on the oxidation state of the metal centre; though comparable HFCCs are obtained for systems $\mathbf{3}-\mathbf{M}^{\mathbf{R}}$ and $\mathbf{6}-\mathbf{M}^{\mathbf{R}} \mathbf{X}$ (formally $\mathbf{M}^{\mathrm{III}}$ ), the HFFCs of $\mathbf{7 - \mathbf { M } ^ { \mathbf { R } } \mathbf { X }}$ (formally $\mathrm{M}^{\mathrm{II}}$ ) differ markedly from other results. Both observed trends contrast the conclusions made based on experimental EPR and ENDOR spectra.

A near-excellent agreement between the calculated and experimentally determined HFCCs is found for the spirocyclic aluminum and gallium radicals $\mathbf{3}-\mathbf{A l}^{\mathbf{R}}$ and 3-Ga ${ }^{\mathbf{R}}$, as well as for the monocyclic radicals $6-\mathbf{G a}^{\mathrm{Ph}} \mathbf{I} / \mathbf{6}-\mathbf{G a}^{\mathrm{Dipp}} \mathbf{I}$ and $\mathbf{6}-\mathbf{I n}^{{ }^{\mathrm{Ph}}} \mathbf{C l} / \mathbf{6}-\mathbf{I n}^{\mathrm{Dipp}} \mathbf{C l}$. However, very poor or no agreement is found for the monocycles $\mathbf{6}-\mathbf{A l}^{\mathbf{P h}}{ }_{\mathbf{I}} / \mathbf{6}-\mathbf{A l} \mathbf{A i p p}_{\mathbf{I}}$ and $\mathbf{6}$ $\mathbf{G a}^{\mathbf{t B u}} \mathbf{I}$, and for the dimeric diradicals $\mathbf{7 -} \mathbf{M}^{\mathbf{R}} \mathbf{x}$. Theoretical calculations and a re-evaluation of the experimental data indicated that in the case of dimeric diradicals, the paramagnetic species characterized in solution by EPR and ENDOR spectroscopies are not the same radicals that were identified in the solid state by X-ray crystallography: in solution the Dipp-substituted diradicals $\quad$ 7-Ga ${ }^{\text {Dipp }}{ }_{\mathbf{B r}}, \quad$ 7-Ga $\mathbf{G i p p}_{\mathbf{I}}$ and $\quad \mathbf{7 - I n}^{\text {Dipp }} \mathbf{C l}$ undergo disproportionation reactions and form the mono- and spirocycles $\mathbf{6 - G a} \mathbf{G i p p}_{\mathbf{B r}}, \mathbf{3 - G a}{ }^{\text {Dipp }}$, and 6-In ${ }^{\text {Dipp }} \mathbf{C l}$, respectively. It was also demonstrated that the radical species contributing to the experimental EPR spectrum of $\mathbf{7 - G} \mathbf{G}^{\mathbf{t B u}} \mathbf{I}$ is the same species observed in the EPR spectrum of 6-Ga ${ }^{\text {Dipp }} \mathbf{I}$; definite identification of this paramagnetic system could not, however, be given.

The present study clearly demonstrates the ability of theoretical methods to produce realistic spin densities and, hence, accurate EPR hyperfine coupling constants. Such data is indispensable in the analysis of EPR spectra of inorganic compounds which 
are often complicated by the presence of a number of nuclei with several magnetically active isotopes, and are thus readily misinterpreted.

\section{Computational Details}

The geometries of all compounds were optimized in their ground states using DFT. The calculations utilized the hybrid PBE0 exchange-correlation functional ${ }^{21}$ and Ahlrichs' triple-zeta valence basis sets augmented by one set of polarization functions (TZVP). ${ }^{22}$

For iodine and indium, the corresponding ECP basis sets were used. ${ }^{22}$ The PBE0 hybrid density functional was chosen on the grounds of several published benchmarks that have shown it to perform well in calculating molecular properties for a wide variety of chemical systems. ${ }^{23}$ The way in which the PBE0 functional is constructed and the lack of empirical parameters fitted to specific physical properties also make it appealing from a purely theoretical standpoint. Appropriate molecular point groups were used to improve the efficiency of the calculations. All geometry optimizations were done with the Turbomole 5.7.1 $1^{24}$ and Gaussian $03^{25}$ program packages.

Hyperfine coupling constants were calculated for all paramagnetic systems in their geometry optimized structures by using both non-relativistic and fully relativistic methods and the unrestricted Kohn-Sham formalism. The non-relativistic calculations utilized the same basis sets and density functional as the geometry optimizations; several benchmarks have recently been published which demonstrate the suitability of TZVP basis set for the calculation of EPR parameters. ${ }^{26}$ For the heavier nuclei indium and iodine, the use of ECPs prevents the direct determination of HFCCs using the same method. In addition, relativistic calculations are essential in order to obtain more than a 
qualitative accuracy. Thus, relativistic calculations for all systems with In and I atoms were carried out. The calculations utilized the large QZ4P STO basis set, the PBEPBE GGA functional ${ }^{21 \mathrm{a}-\mathrm{c}}$ as well as the scalar-relativistic ZORA formalism. The hyperfine coupling constant calculations were done with the Gaussian $03^{25}$ (non-relativistic) and ADF $2004.01^{27}$ program packages (relativistic). The values reported in Tables 2, 3, and 4 are non-relativistic for the lighter nuclei and scalar-relativistic for the heavier atoms indium and iodine.

\section{Acknowledgements}

The authors gratefully acknowledge the Academy of Finland (H. M. T.) and the McMaster University (A. F. A.) for financial support.

\section{References and notes}

1 For a review, see: G. van Koten, K. Vrieze, Adv. Organomet. Chem., 1982, 21, 151.

2 J. A. Fernandes, R. A. Sa Ferreira, M. Pillinger, L. D. Carlos, I. S. Goncalves, P. J. A. Ribeiro-Claro, Eur. J. Inorg. Chem., 2004, 19, 3913.

3 M. Denk, R. Lennon, R. Hayashi, R. West, A. V. Belyakov, H. P. Verne, A. Haaland, M. Wagner, N. Metzler, J. Am. Chem. Soc., 1994, 116, 2691.

4 W. A. Hermann, M. Denk, J. Behm, W. Scherer, F. R. Klingan, H. Bock, B. Soluki, M. Wagner, Angew. Chem., Int. Ed. Engl., 1992, 31, 1485.

5. (a) S. Warwel, B. Wiege, E. Fehling, M. Kunz, Macromol. Chem. Phys., 2001, 202, 849; (b) G. A. Grasa, A. C. Hillier, S. P. Nolan, Org. Lett., 2001, 3, 1077; (c) G. A. Grasa, R. Singh, E. D. Stevens, S. P. Nolan, J. Organomet. Chem., 2003, 687, 269; 
(d) A. Valente, J. Moreira, A. D. Lopes, M. Pillinger, C. D. Nunes, C. C. Romao, F. E. Kuehn, I. S. Goncalves, New J. Chem., 2004, 28, 308.

6. (a) D. S. Brown, A. Decken, C. A. Schnee, A. H. Cowley, Inorg. Chem., 1995, 34, 6415; (b) J. A. C. Clyburne, R. D. Culp, S. Kamepalli, A. H. Cowley, A. Decken, Inorg. Chem., 1996, 35, 6651; (c) D. S. Brown, A. Decken, A. H. Cowley, J. Am. Chem. Soc., 1995, 117, 5421; (d) C. Cui, H. W. Roesky, H.-G. Schmidt, N. Noltemeyer, H. Hao, F. Cimpoescu, Angew. Chem., Int. Ed., 2000, 39, 4274; (e) E. S. Schmidt, A. Jokisch, H. Schmidbaur, J. Am. Chem. Soc., 1999, 121, 9758; (f) T. Pott, P. Jutzi, B. Neumann, H.-G. Stammler, Organometallics, 2001, 20, 1965.

7 A. J. Arduengo III, R. L. Harlow, M. Kline, J. Am. Chem. Soc., 1991, 113, 361.

8 (a) C. Corvaja, L. Pasimeni, Chem. Phys. Lett., 1976, 39, 261; (b) M. Kaupp, H. Stoll, H. Preuss, W. Kaim, T. Stahl, G. van Koten, E. Wissing, W. J. J. Smeets, A. L. Spek, J. Am. Chem. Soc., 1991, 113, 5606.

9 M. G. Gardiner, G. R. Hanson, M. J. Henderson, F. C. Lee, C. L. Raston, Inorg. Chem., 1994, 33, 2456.

10 S. Richter, C. Daul, A. v. Zelewsky, Inorg. Chem., 1976, 15, 943.

11 (a) N. F. G. Cloke, G. R. Hanson, M. J. Henderson, P. B. Hitchcock, C. L. Raston, J. Chem. Soc., Chem. Commun., 1989, 1002; (b) N. F. G. Cloke, C. I. Dalby, M. J. Henderson, P. B. Hitchcock, C. H. L. Kennard, R. N. Lamb, C. L. Raston, J. Chem. Soc., Chem. Commun., 1990, 1394; (c) M. G. Gardiner, C. L. Raston, B. W. Skelton, A. H. White, Inorg. Chem., 1997, 36, 2795; (d) T. Pott, P. Jutzi, W. Kaim, W. W. Schoeller, B. Neumann, A. Stammler, H.-G. Stammler, M. Wanner, Organometallics, 2002, 21, 3169; (e) R. J. Baker, R. D. Farley, C. Jones, M. Kloth, D. M. Murphy, J. Chem. Soc., Dalton. Trans., 2002, 3844; ( $f$ ) R. J. Baker, R. D. Farley, C. Jones, M. 
Kloth, D. M. Murphy, Chem. Commun., 2002, 1196; (g) K. L. Antcliff, R. J. Baker, C. Jones, D. M. Murphy, R. P. Rose, Inorg. Chem., 2005, 44, 2098; (h) R. J. Baker, R. D. Farley, C. Jones, D. P. Mills, M. Kloth, D. M. Murphy, Chem. Eur. J., 2005, 11, 2972.

12 (a) W. Kaim, W. Matheis, J. Chem. Soc., Chem. Commun., 1991, 597; (b) N. F. G. Cloke, C. I. Dalby, P. J. Daff, J. C. Green, J. Chem. Soc., Dalton Trans., 1991, 181.

13 (a) N. Kaltsoyannis, J. Chem. Soc., Dalton Trans., 1996, 1583; (b) W. W. Schoeller, S. Grigoleit, J. Chem. Soc., Dalton Trans., 2002, 405.

14 T. Chivers, D. J. Eisler, C. Fedorchuk, G. Schatte, H. M. Tuononen, R. T. Boeré, Chem. Commun., 2005, 3930.

15 A. Armstrong, T. Chivers, H. M. Tuononen, M. Parvez, Inorg. Chem., 2005, 44, 5778.

16 J. A. Weil, J. R. Bolton, J. E. Wertz in Electron Paramagnetic Resonance: Elementary Theory and Practical Applications, Wiley-Interscience, New York, 1994, pp. 534-535.

17 B. Engels in Calculation of NMR and EPR Parameters. Theory and Applications. Eds. M. Kaupp, M. Bühl, and V. G. Malkin, Wiley-VCH, Weinheim, 2004, pp. 483-492.

18 H. M. Tuononen, A. Armstrong, Inorg. Chem., 2005, 44, 8277.

19 R. J. Baker, C. Jones, Dalton Trans., 2005, 1341.

20 The simulation was created using WINEPR SimFonia program: Bruker Analytische Messtechnik GmbH, WINEPR SimFonia version 1.25, 1996. 
21 (a) J. P. Perdew, K. Burke, M. Ernzerhof, Phys. Rev. Lett., 1996, 77, 3865; (b) J. P. Perdew, K. Burke, M. Ernzerhof, Phys. Rev. Lett., 1997, 78, 1396; (c) J. P. Perdew, M. Ernzerhof, K. Burke, J. Chem. Phys., 1996, 105, 9982; (d) M. Ernzerhof, G. E. Scuseria, J. Chem. Phys., 1999, 110, 5029.

22 The basis sets were used as they are referenced in the Turbomole 5.7.1 internal basis set library.

23 (a) C. Adamo, V. Barone, J. Chem. Phys., 1999, 110, 6158; (b) C. Adamo, V. Barone, Chem. Phys. Lett., 1998, 298, 113; (c) C. Adamo, V. Barone, J. Mol. Struc. (Theochem), 1999, 493, 145; (d) C. Adamo, V. Barone, Theor. Chem. Acc., 2000, $105,169$.

24 R. Ahlrichs, et al., TURBOMOLE, Program Package for ab initio Electronic Structure Calculations, Version 5.7.1, University of Karlsruhe, Karlsruhe (Germany), 2004.

25 M. J. Frisch, G. W. Trucks, H. B. Schlegel, G. E. Scuseria, M. A. Robb, J.R. Cheeseman, J. A. Montgomery, Jr., T. Vreven, K. N. Kudin, J. C. Burant, J. M. Millam, S. S. Iyengar, J. Tomasi, V. Barone, B. Mennucci, M. Cossi, G. Scalmani, N. Rega, G. A. Petersson, H. Nakatsuji, M. Hada, M. Ehara, K. Toyota, R. Fukuda, J. Hasegawa, M. Ishida, T. Nakajima, Y. Honda, O. Kitao, H. Nakai, M. Klene, X. Li, J. E. Knox, H. P. Hratchian, J. B. Cross, C. Adamo, J. Jaramillo, R. Gomperts, R. E. Stratmann, O. Yazyev, A. J. Austin, R. Cammi, C. Pomelli, J. W. Ochterski, P. Y. Ayala, K. Morokuma, G. A. Voth, P. Salvador, J. J. Dannenberg, V. G. Zakrzewski, S. Dapprich, A. D. Daniels, M. C. Strain, O. Farkas, D. K. Malick, A. D. Rabuck, K. Raghavachari, J. B. Foresman, J. V. Ortiz, Q. Cui, A. G. Baboul, S. Clifford, J. Cioslowski, B. B. Stefanov, G. Liu, A. Liashenko, P. Piskorz, I. Komaromi, R. L. 
Martin, D. J. Fox, T. Keith, M. A. Al-Laham, C. Y. Peng, A. Nanayakkara, M. Challacombe, P. M. W. Gill, B. Johnson, W. Chen, M. W. Wong, C. Gonzalez, and J. A. Pople, Gaussian 03, (Revision C.02), Gaussian, Inc., Pittsburgh, PA, 2003.

26 (a) L. Hermosilla, P. Calle, J. M. Garcia de la Vega, C. Sieiro, J. Phys. Chem. A, 2005, 109, 1114; (b) M. T. Nguyen, S. Creve, L. G. Vanquickenborne, J. Phys. Chem. A, 1997, 101, 3174; (c) M. T. Nguyen, S. Creve, L. A. Eriksson, L. G. Vanquickenborne, Mol. Phys., 1997, 91, 537.

27 ADF2004.01, SCM, Theoretical Chemistry, Vrije Universiteit, Amsterdam (The Netherlands), http://www.scm.com. 
Table 1 Calculated and experimental geometrical parameters of spirocyclic group 13 diazabutadiene complexes $\mathbf{3}-\mathbf{M}^{\mathbf{R}} a$

\begin{tabular}{|c|c|c|c|c|c|c|}
\hline Parameter & $\begin{array}{l}\mathbf{A l}^{\mathbf{t B u}} \\
\text { Calc. }\end{array}$ & $\begin{array}{c}\text { AltBu }^{\mathbf{t B u}} \\
\text { Exptl. }^{b}\end{array}$ & $\begin{array}{l}\mathbf{G a}^{\mathbf{t B u}} \\
\text { Calc. }\end{array}$ & $\begin{array}{c}\mathbf{G a}^{\mathbf{t B u}} \\
\text { Exptl. }^{c}\end{array}$ & $\begin{array}{l}\mathbf{G a}^{\mathbf{P h}} \\
\text { Calc. }\end{array}$ & $\begin{array}{l}\mathbf{G a}^{\text {Dipp }} \\
\text { Exptl. }^{d}\end{array}$ \\
\hline $\mathrm{r} \mathrm{MN}(1)$ & 1.841 & 1.823 & 1.881 & 1.864 & 1.885 & 1.901 \\
\hline $\mathrm{r} \mathrm{N}(1) \mathrm{C}(1)$ & 1.402 & 1.415 & 1.397 & 1.395 & 1.394 & 1.392 \\
\hline r C $(1) \mathrm{C}\left(1^{*}\right)$ & 1.347 & 1.343 & 1.348 & 1.350 & 1.348 & 1.338 \\
\hline $\mathrm{r} \mathrm{N}(1) \mathrm{C}(3)$ & 1.457 & 1.470 & 1.456 & 1.475 & 1.383 & 1.438 \\
\hline$\angle \mathrm{N}(1) \mathrm{MN}(1 *)$ & 92.2 & 92.3 & 90.6 & 90.4 & 89.9 & 88.3 \\
\hline$\angle \mathrm{MN}(1) \mathrm{C}(1)$ & 106.2 & 106.8 & 106.4 & 107.2 & 106.8 & 107.7 \\
\hline$\angle \mathrm{MN}(1) \mathrm{C}(3)$ & 135.1 & 134.4 & 133.8 & 132.0 & 129.3 & 140.2 \\
\hline $\mathrm{r} \mathrm{MN}(2)$ & 1.946 & 1.920 & 1.996 & 1.970 & 1.972 & 2.007 \\
\hline $\mathrm{r} \mathrm{N}(2) \mathrm{C}(2)$ & 1.327 & 1.339 & 1.326 & 1.326 & 1.334 & 1.332 \\
\hline $\mathrm{r} \mathrm{C}(2) \mathrm{C}\left(2^{*}\right)$ & 1.401 & 1.395 & 1.401 & 1.389 & 1.393 & 1.387 \\
\hline $\mathrm{r} \mathrm{N}(2) \mathrm{C}(4)$ & 1.474 & 1.483 & 1.472 & 1.485 & 1.396 & 1.449 \\
\hline$\angle \mathrm{N}(2) \mathrm{MN}(2 *)$ & 85.1 & 86.1 & 83.6 & 84.9 & 84.4 & 82.1 \\
\hline$\angle \mathrm{MN}(2) \mathrm{C}(2)$ & 109.9 & 109.4 & 109.9 & 109.0 & 109.8 & 110.0 \\
\hline$\angle \mathrm{MN}(2) \mathrm{C}(4)$ & 130.0 & 130.9 & 129.3 & 130.3 & 126.3 & 136.3 \\
\hline$\angle \mathrm{N}(1) \mathrm{MN}(2)$ & 120.7 & 120.5 & 121.6 & 121.3 & 119.5 & 125.3 \\
\hline
\end{tabular}

${ }^{a}$ Average values of experimental parameters are reported. ${ }^{b}$ Reference $11 \mathrm{a} .{ }^{c}$ Reference 11b. ${ }^{d}$ Reference $11 \mathrm{~h}$. 
Table 2 Calculated and experimental hyperfine coupling constants of spirocyclic group 13 diazabutadiene complexes 3-M $\mathbf{M}^{\mathbf{R} a}$

\begin{tabular}{lcccccc}
\hline$\left[(\mathrm{R}-\mathrm{DAB})_{2} \mathrm{M}\right]^{\bullet}$ & $\mathrm{R}$ & $\mathrm{M}$ & ${ }^{14} \mathrm{~N}(1)$ & ${ }^{1} \mathrm{H}(1)$ & ${ }^{14} \mathrm{~N}(2)$ & ${ }^{1} \mathrm{H}(2)$ \\
\hline $\mathrm{M}={ }^{27} \mathrm{Al}$ & $\mathrm{H}$ & -6.1 & 2.7 & -7.0 & 1.3 & 0.6 \\
& $\mathrm{Me}$ & -6.5 & 3.4 & -6.2 & 1.2 & 0.5 \\
& ${ }^{\mathrm{t}} \mathrm{Bu}^{b}$ & $-6.9(5)$ & $3.6(5)$ & $-6.1(5)$ & $1.1(-)$ & $0.5(-)$ \\
& $\mathrm{Ph}$ & -6.4 & 3.1 & -5.0 & 1.0 & -0.1 \\
$\mathrm{M}={ }^{69} \mathrm{Ga}$ & $\mathrm{H}$ & -21.5 & 3.4 & -6.7 & 1.7 & 0.7 \\
& $\mathrm{Me}$ & -22.6 & 4.2 & -5.8 & 1.7 & 0.6 \\
& ${ }^{\mathrm{t}} \mathrm{Bu}$ & $-23.3(18)$ & $4.3(-)$ & $-5.8(-)$ & $1.4(-)$ & $0.6(-)$ \\
& $\mathrm{Ph} /$ & $-19.9 /$ & $3.7 /$ & $-5.0 /$ & $1.0 /$ & $0.3 /$ \\
& $\mathrm{Dipp}$ & $(17.0)$ & $(6.0)$ & $(5.8)$ & $(-)$ & $(-)$ \\
& & & & & & \\
$\mathrm{M}={ }^{115} \mathrm{In}$ & $\mathrm{H}$ & -33.4 & 3.7 & -6.4 & 1.3 & 0.5 \\
& $\mathrm{Me}$ & -34.1 & 4.5 & -5.6 & 1.2 & 0.4 \\
& ${ }^{\mathrm{t}} \mathrm{Bu}$ & -34.8 & 4.6 & -5.6 & 1.0 & 0.4 \\
& $\mathrm{Ph}$ & -29.5 & 3.9 & -5.0 & 0.7 & 0.2 \\
\hline
\end{tabular}

${ }^{a}$ Values reported in Gauss $(1 \mathrm{G}=0.1 \mathrm{mT})$. Experimental results in parenthesis. ${ }^{b}$ Reference 11a. ${ }^{c}$ Reference $11 \mathrm{~h}$.

Table 3 Calculated and experimental hyperfine coupling constants of monocyclic group 13 diazabutadiene radicals $\mathbf{6}-\mathbf{M}^{\mathbf{R}} \mathbf{x}^{a}$

\begin{tabular}{lccccc}
\hline$\left[(\mathrm{R}-\mathrm{DAB}) \mathrm{MX}_{2}\right]^{\bullet}$ & $\mathrm{R}$ & $\mathrm{M}$ & ${ }^{14} \mathrm{~N}$ & ${ }^{1} \mathrm{H}$ & $\mathrm{X}$ \\
\hline $\mathrm{M}={ }^{27} \mathrm{Al} ; \mathrm{X}={ }^{127} \mathrm{I}$ & $\mathrm{Ph} /$ & $-8.4 /$ & $3.7 /$ & $-6.6 /$ & $6.8 /$ \\
& $\mathrm{Dipp}^{b}$ & $(2.9)$ & $(6.8)$ & $(6.0)$ & $(0.4)$ \\
$\mathrm{M}={ }^{69} \mathrm{Ga} ; \mathrm{X}={ }^{127} \mathrm{I}$ & $\mathrm{Bu}^{b}$ & $-25.8(1.3)$ & $4.5(8.6)$ & $-5.8(1.4)$ & $11.9(1.3)$ \\
& $\mathrm{Ph} /$ & $-24.2 /$ & $4.3 /$ & $-6.3 /$ & $8.9 /$ \\
& $\mathrm{Dipp}^{c}$ & $(25)$ & $(7)$ & $(4)$ & $(8)$ \\
& & & & & \\
$\mathrm{M}={ }^{115} \mathrm{In} ; \mathrm{X}={ }^{37} \mathrm{Cl}$ & $\mathrm{Ph} /^{2}$ & $-33.7 /$ & $4.6 /$ & $-6.2 /$ & $1.0 /$ \\
& $\mathrm{Dipp}^{d}$ & $(26)$ & $(5)$ & $(5)$ & $(-)$ \\
\hline
\end{tabular}

${ }^{a}$ Values reported in Gauss $(1 \mathrm{G}=0.1 \mathrm{mT})$. Experimental results in parenthesis. ${ }^{b}$ Reference 11e. ${ }^{c}$ Reference $11 \mathrm{~d} .{ }^{d}$ Reference $11 \mathrm{~h}$. 
Table 4 Calculated and experimental hyperfine coupling constants of dimeric group 13

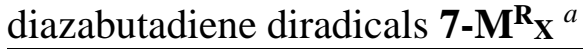

\begin{tabular}{lccccc}
\hline$\left\{[(\mathrm{R}-\mathrm{DAB}) \mathrm{MX}]_{2}\right\}^{\bullet \bullet}$ & $\mathrm{R}$ & $\mathrm{M}$ & ${ }^{14} \mathrm{~N}$ & ${ }^{1} \mathrm{H}$ & $\mathrm{X}$ \\
\hline $\mathrm{M}={ }^{69} \mathrm{Ga} ; \mathrm{X}={ }^{81} \mathrm{Br}$ & $\mathrm{Ph} /$ & $2.9 /$ & $2.2 /$ & $-2.8 /$ & $5.5 /$ \\
$\mathrm{M}={ }^{69} \mathrm{Ga} ; \mathrm{X}={ }^{127} \mathrm{I}$ & $\mathrm{Dipp}^{b}$ & $(22.5)$ & $(6.0)$ & $(5.8)$ & $(1.5)$ \\
& ${ }^{\mathrm{t}} \mathrm{Bu}^{c}$ & $11.2(1.2)$ & $2.5(8.4)$ & $-2.8(1.4)$ & $12.5(1.3)$ \\
& $\mathrm{Ph} /^{2}$ & $3.6 /$ & $2.2 /$ & $-2.8 /$ & $6.6 /$ \\
& $\mathrm{Dipp}^{b}$ & $(17.0)$ & $(6.0)$ & $(5.8)$ & $(0.4)$ \\
& & & & & \\
$\mathrm{M}={ }^{115} \mathrm{In} ; \mathrm{X}={ }^{35} \mathrm{Cl}$ & $\mathrm{Ph} /^{2}$ & $4.3 /$ & $2.2 /$ & $-2.6 /$ & $0.9 /$ \\
& $\mathrm{Dipp}^{d}$ & $(26.2)$ & $(5)$ & $(5)$ & $(-)$ \\
\hline
\end{tabular}

${ }^{a}$ Values reported in Gauss $(1 \mathrm{G}=0.1 \mathrm{mT})$. Experimental results in parenthesis. ${ }^{b}$ Reference 11h. ${ }^{c}$ Reference 11e. ${ }^{d}$ Reference $11 \mathrm{f}$. 


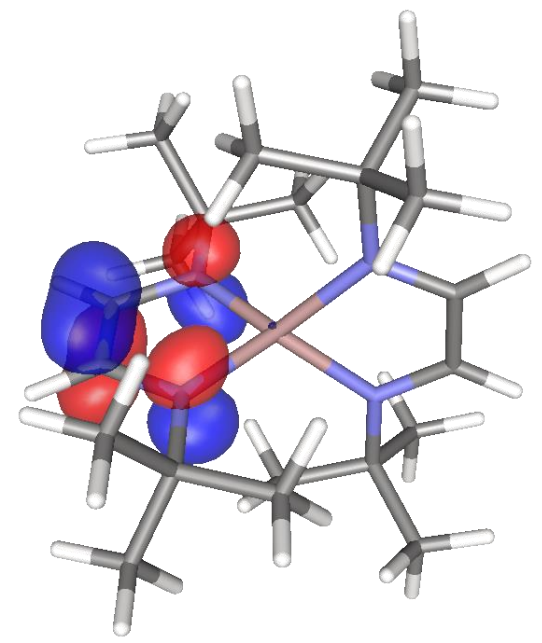

Fig. 1 The $\mathrm{SOMO}$ of $\left[\left({ }^{\mathrm{t}} \mathrm{Bu}-\mathrm{DAB}\right)_{2} \mathrm{Al}\right]^{\bullet}$ at isosurface levels \pm 0.06 . 


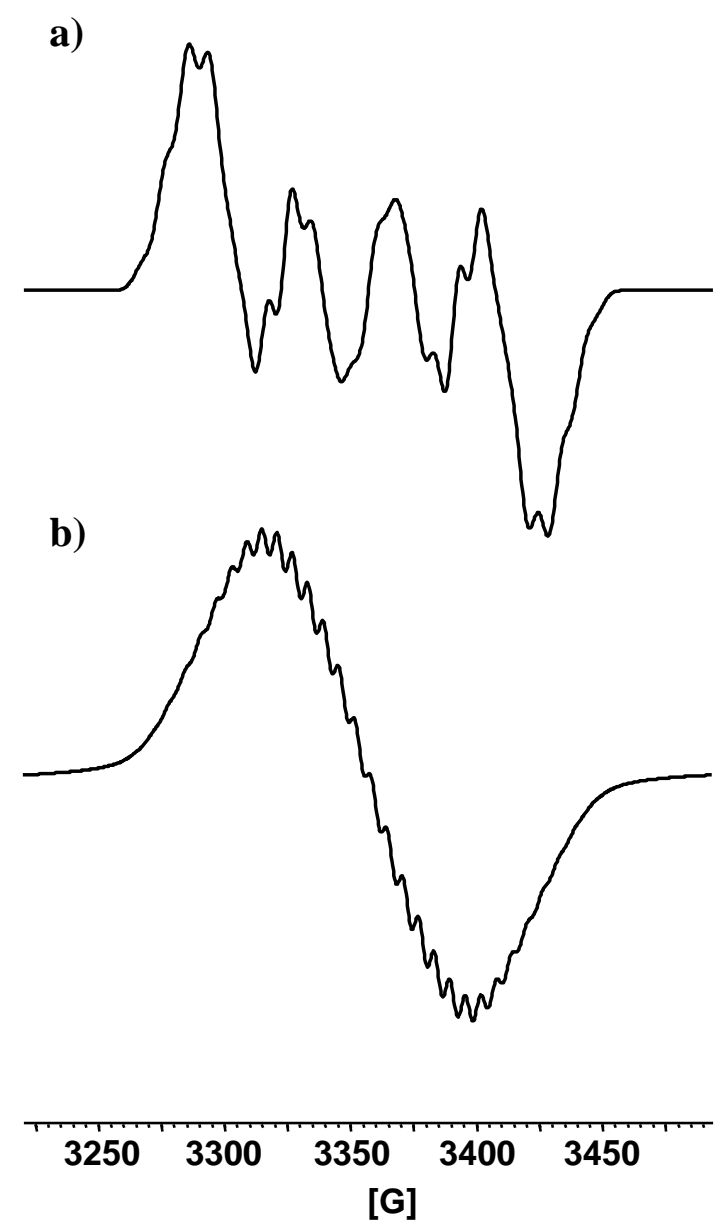

Fig. 2 The simulated EPR spectrum of $\left\{[(\text { Dipp-DAB }) \mathrm{GaBr}]_{2}\right\}^{\bullet \bullet}$ using HFCCs $(a)$ reported in the literature and $(b)$ determined for $\left[(\text { Dipp-DAB }) \mathrm{GaBr}_{2}\right]^{\bullet}$ in this work (line width $=6.5 \mathrm{G})$. 